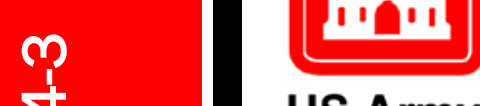

US Army Corps of Engineers ${ }_{\circledast}$

Engineer Research and

Development Center

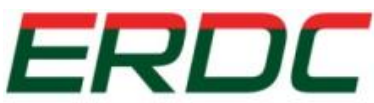

INNOVATIVE SOLUTIONS for a safer, better world

Wetlands Regulatory Assistance Program (WRAP)

\title{
Use of LiDAR to Assist in Delineating Waters of the United States, Including Wetlands
}

Jennifer Gillrich and Robert Lichvar

March 2014 
The US Army Engineer Research and Development Center (ERDC) solves the nation's toughest engineering and environmental challenges. ERDC develops innovative solutions in civil and military engineering, geospatial sciences, water resources, and environmental sciences for the Army, the Department of Defense, civilian agencies, and our nation's public good. Find out more at www.erdc.usace.army.mil.

To search for other technical reports published by ERDC, visit the ERDC online library at http://acwc.sdp.sirsi.net/client/default. 


\section{Use of LiDAR to Assist in Delineating Waters of the United States, Including Wetlands}

Jennifer Gillrich and Robert Lichvar

Cold Regions Research and Engineering Laboratory (CRREL)

US Army Engineer Research and Development Center

72 Lyme Road

Hanover, NH 03755-1290

Final report

Approved for public release; distribution is unlimited.

Prepared for Wetlands Regulatory Assistance Program (WRAP)

US Army Corps of Engineers

Vicksburg, MS 39180-6133 


\section{Abstract}

During preliminary delineations of an Ordinary High Water Mark (OHWM) boundary, LiDAR data or products may be used to view the OHWM signature across a project area and to estimate the height and location of two primary OHWM indicators: changes in vegetation and breaks in slope. At this time, most LiDAR data or products cannot detect changes in sediment texture. The point spacing, horizontal resolution, and vertical accuracy of the data or products determine if landscape features, such as the OHWM break in slope, can be measured with sufficient accuracy. All information gathered from LiDAR data or products should be verified in the field. During the preliminary, data-gathering stage of wetland delineations, LiDAR data and products may be used to view vegetative, topographic, and hydrologic patterns across a project area and to focus the investigation on transitional areas. They cannot provide evidence of hydrophytic vegetation or hydric soils. Although LiDAR intensity data may provide information on inundation extent, they contain no information regarding inundation frequency or duration and should not be used as a primary hydrology indicator. Intensity data collected during the growing season could be used as a secondary indicator of wetland hydrology. LiDAR data or products are not an adequate substitute for a field investigation.

DISCLAIMER: The contents of this report are not to be used for advertising, publication, or promotional purposes. Citation of trade names does not constitute an official endorsement or approval of the use of such commercial products. All product names and trademarks cited are the property of their respective owners. The findings of this report are not to be construed as an official Department of the Army position unless so designated by other authorized documents. 


\title{
Table of Contents
}

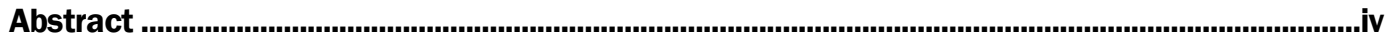 \\ List of Figures ................................................................................................................................vi

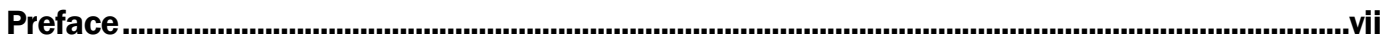

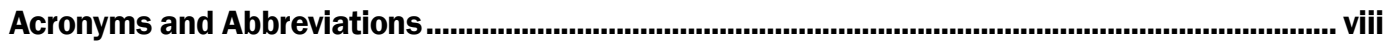 \\ Unit Conversion Factors ............................................................................................................... xi
}

1 Introduction ................................................................................................................................ 1

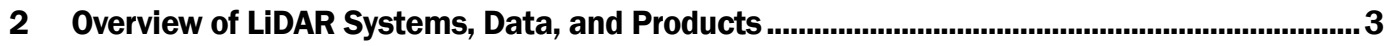

2.1 LiDAR systems and data collection methods ....................................................... 3

2.2 Processing LiDAR data: point clouds, models, and LiDAR-derived products.............. 8

2.3 Metrics for evaluating LiDAR data ................................................................ 14

2.4 Current federal LiDAR guidelines ........................................................................ 19

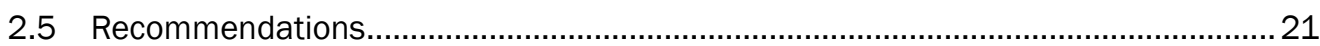

3 Using LiDAR Data in Preliminary OHWM Delineations .............................................................22

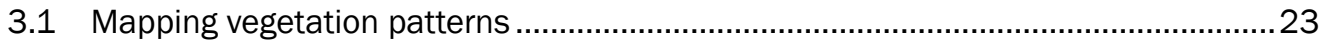

3.2 Mapping topographic patterns and channel morphology.....................................26

3.3 Mapping changes in sediment texture .................................................................. 29

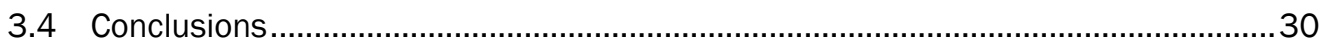

\section{Using LiDAR Data in the Preliminary Data-Gathering Stage of Wetland}

Delineations .................................................................................................................................32

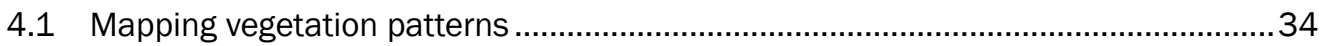

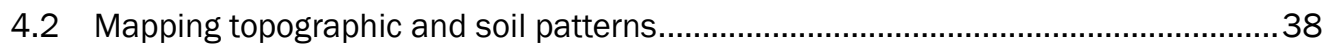

4.3 Mapping hydrologic patterns ........................................................................ 42

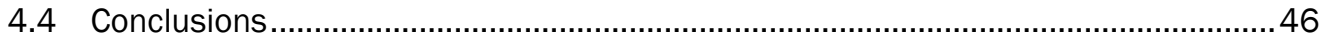

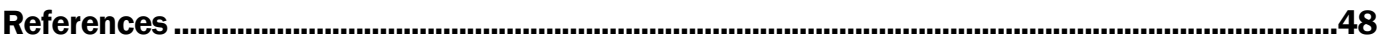

Appendix A: Software for Viewing and Managing LiDAR Data and Products .............................54

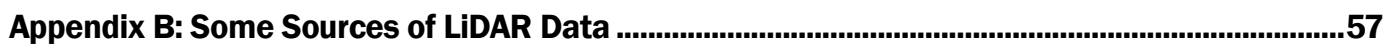

Report Documentation Page 


\section{List of Figures}

1 Comparison of discrete return and full waveform airborne laser measurements for different target situations. The target is illuminated with a short laser pulse, and when the pulse interacts diffusely with a target, a fraction of the signal is reflected back to the instrument. Multiple surfaces are well characterized using a full waveform system whereas a discrete return system often fails to detect all surfaces in complex or cluttered target environments. (Adapted from Riegl Lasar Measurement Systems [2012].)

2 Point cloud from Mission Creek, CA, collected using an aerial platform and a waveform digitizer, the National Aeronautics and Space Administration's Airborne Topographic Mapper. In the legend, elevation is measured in meters. The point cloud is displayed using Quick Terrain Reader 7.1.6 (Applied Imagery 2012)

3 Comparison of (a) a 37,706 kB DTM (1,509,218 points) and (b) a 144,526-kB point cloud $(5,780,445$ points). Both images were produced from the same data collected from a terrestrial platform with a waveform digitizer in Ascutney, VT. The data are colorized by elevation. The legends are displayed in meters. The data are displayed using Quick Terrain Reader 7.1.6 (Applied Imagery 2012) .....

4 Comparison of two floodplain maps of the Humboldt River Valley in northwestern NV

5 Digital Terrain Model (DTM) derived from LiDAR data collected using a terrestrial platform in eastern Vermont and displayed using Quick Terrain Reader 7.1.6 (Applied Imagery 2012). In the legend, height is measured in meters. Elevation of the bank and the swale are used to calculate slope (0.18) over a distance of $15 \mathrm{~m}$.

6 Comparison of three LiDAR products and four other types of remotely sensed data for a hypothetical wetland delineation near Davis Park on Fire Island, New York 


\section{Preface}

This research was funded by the US Army Corps of Engineers, Wetland Regulatory Assistance Program (WRAP).

The principal investigators were J ennifer Gillrich and Robert Lichvar, both of the Remote Sensing/ Geographic Information Systems (RS/ GIS) and Water Resources Branch, US Army Engineer Research and Development Center (ERDC), Cold Regions Research and Engineering Laboratory (CRREL), Hanover, NH. This study was conducted under the general supervision of Timothy Pangburn, Chief, RS/ GIS and Water Resources Branch; Dr. J ustin B. Berman, Chief, Research and Engineering Division; Dr. Lance Hansen, Deputy Director; and Dr. Robert E. Davis, Director.

COLJ effrey R. Eckstein was the Commander of ERDC, and Dr. J effery P. Holland was the Director.

The authors thank David Finnegan and Adam LeWinter from ERDCCRREL for providing point-cloud data used in many of the figures and for their technical reviews of this manuscript. David Shaeffer from USACE's Raleigh Field Office provided valuable unpublished resources and technical review. Elias Deeb, Steven Gaughan, Lindsey Lefevbre, Mathew Mersel, and J eanne Roningen, all from ERDC-CRREL, David Lekson from the Wilmington District, and Katherine Curtis contributed many insights. All are thanked for their thoughtful criticisms. 


\section{Acronyms and Abbreviations}

\begin{tabular}{|c|c|}
\hline ALS & Aerial Laser Scanning \\
\hline BLM & Bureau of Land Management \\
\hline BONAP & Biota of North America Program \\
\hline CAM & Canopy Altitude Model \\
\hline $\mathrm{CHM}$ & Canopy Height Model \\
\hline CLICK & Center for LiDAR Information Coordination and Knowledge \\
\hline $\mathrm{COP}$ & Community of Practice \\
\hline CRREL & US Army Cold Regions Research and Engineering Laboratory \\
\hline DEM & Digital Elevation Model \\
\hline DSM & Digital Surface Model \\
\hline DTM & Digital Terrain Model \\
\hline EAARL & NASA's Experimental Airborne Advanced Research LiDAR \\
\hline ESRI & Environmental Systems Resource Institute \\
\hline FEMA & Federal Emergency Management Agency \\
\hline FGDC & Federal Geographic Data Committee \\
\hline FVA & Fundamental Vertical Accuracy \\
\hline FWS & US Fish and Wildlife Service \\
\hline GEP & Google Earth Pro \\
\hline GIS & Geographic Information Systems \\
\hline GPS & Global Positioning System \\
\hline IMU & Inertial Measurement Unit \\
\hline
\end{tabular}




\begin{tabular}{|c|c|}
\hline JALBTCX & J oint Aerial Lidar Bathymetry Technical Center of Expertise \\
\hline KML & Keyhole Markup Language \\
\hline LAS & Log ASCII Standard \\
\hline LCT & Land Cover Type \\
\hline LiDAR & Light Detection and Ranging \\
\hline MLS & Mobile Laser Scanning \\
\hline NCALM & National Center for Airborne Laser Mapping \\
\hline NCED & National Center for Earth-Surface Dynamics \\
\hline NDEP & National Digital Elevation Program \\
\hline NED & National Elevation Dataset \\
\hline NLCD & National Land Cover Data \\
\hline NOAA & National Oceanic and Atmospheric Administration \\
\hline NPS & National Park Service \\
\hline NRCS & Natural Resources Conservation Service \\
\hline NWI & National Wetland Inventory \\
\hline $\mathrm{OA}$ & Overall Accuracy \\
\hline OHWM & Ordinary High Water Mark \\
\hline PA & Producer's Accuracy \\
\hline RMSE & Root Mean Square Error \\
\hline RS/GIS & Remote Sensing/ Geographic Information Systems \\
\hline TIN & Triangulated Irregular Network \\
\hline TLS & Terrestrial Laser Scanning \\
\hline TWI & Topographic Wetness Indices \\
\hline UA & User's Accuracy \\
\hline
\end{tabular}




$\begin{array}{ll}\text { ULEM } & \text { Universal LiDAR Error Model } \\ \text { USACE } & \text { US Army Corps of Engineers } \\ \text { USGS } & \text { US Geological Survey } \\ \text { WoUS } & \text { Waters of the United States } \\ \text { WRAP } & \text { Wetland Regulatory Assistance Program }\end{array}$




\section{Unit Conversion Factors}

\begin{tabular}{|l|l|l|}
\hline Multiply & By & To Obtain \\
\hline acres & $4,046.873$ & square meters \\
\hline feet & 0.3048 & meters \\
\hline hectares & $1.0 \mathrm{E}+04$ & square meters \\
\hline inches & 0.0254 & meters \\
\hline
\end{tabular}




\section{Introduction}

Waters of the United States (WoUS), including wetlands, provide a number of benefits, including, but not limited to, channeling and storing storm waters, recharging aquifers, improving water quality, irrigating crops, providing habitat for wildlife, and providing areas for recreation (Mitsch and Gosselink 2000; Lichvar and Wakeley 2004). Under Section 404 of the Clean Water Act (33 U.S.C. 1344) (US Congress 1977), the US Army Corps of Engineers (USACE) is responsible for regulating the dredging and filling of WoUS and wetlands. To avoid or minimize impacts to channels, the lateral extent of federal jurisdiction-the Ordinary High Water Mark (OHWM) boundary-is delineated in the Arid West, for example, using procedures described in A Field Guide to the Identification of the Ordinary High Water Mark (OHWM) in the Arid West Region of the Western United States (Lichvar and McColley 2008). Likewise, the boundaries of three-factor wetlands are delineated using procedures in the Corps of Engineers Wetlands Delineation Manual (Environmental Laboratory 1987) and the appropriate regional supplement. Our review, requested by the Wetland Regulatory Assistance Program, investigates the feasibility of using LiDAR data for delineation purposes in WoUS and wetlands.

Section Two begins with a general description of Light Detection and Ranging (LiDAR) systems and recognizes the rapidly advancing state of this technology. To develop an understanding of what LiDAR data represent and which data may be useful for delineation purposes, it discusses data collection and processing methods and common geospatial products. Additionally, it reviews current federal guidelines for LiDAR data collection and processing, with the acknowledgement that this field is still evolving and that it is currently guided by minimum specification documents but few standards. To determine the feasibility of using LiDAR in regulatory applications, the following sections review ecological research that uses LiDAR data and products. Section 3 examines the use of LiDAR data or products in preliminary delineations of the OHWM boundary with regard to mapping vegetation patterns, topographic patterns, and changes in sediment texture. Section 4 describes possible uses for LiDAR data or products in preliminary wetland delineations, particularly for mapping topographic, hydrologic, and vegetation patterns. Throughout the report, 
vascular plant scientific names used in vegetation discussions follow Kartesz (2009).

Since it is not typically cost effective to collect original LiDAR data for regulatory purposes, Appendices A and B describe some sources of LiDAR data and products and some freely available LiDAR software and geographic information systems (GIS) packages for viewing and analysis. The figures in this manuscript, created with some of this software, illustrate the different types of LiDAR data and products discussed in this review.

Because LiDAR technology is advancing rapidly, there are temporal limitations to this project. Therefore, we provide specific details on the spatial resolution of the data and the classification accuracy of the LiDAR-derived products used in each study. These details may help investigators gauge the utility of a LiDAR dataset or product, given its spatial resolution. 


\section{Overview of LiDAR Systems, Data, and Products}

The main objective of this review is to discuss the use of LiDAR as it relates to the delineation of WoUS and wetlands, so a basic understanding of what the data represent and how to evaluate data and products is critical. This section provides a brief summary of LiDAR systems, types of data and products, and current accuracy standards so that investigators can assess whatever is available. It begins with a general description of LiDAR systems and the physical properties of electromagnetic radiation as they relate to the amount of spatial detail in a dataset. (For an in-depth review of LiDAR systems, see Deems et al. [2013].) It also describes differences among point clouds, LiDAR models, LiDAR-derived products, and secondary products. Finally, this section discusses metrics for evaluating the spatial resolution of LiDAR data and products and for assessing the accuracy with which LiDAR-derived products classify environmental groupings, such as vegetation or land cover types. Throughout, this section provides current federal standards for LiDAR data accuracy and accuracies reported from the literature.

\subsection{LiDAR systems and data collection methods}

LiDAR point clouds represent the surface of the Earth and objects across the landscape as a collection of points with associated $\mathrm{x}, \mathrm{y}$, and $\mathrm{z}$ location data. Each point is also associated with an intensity value. Before using a point cloud for delineation purposes, it is important to have a basic understanding of how these data are collected and processed because these factors can affect how useful the data may be in regulatory applications. A wide variety of instruments and methodologies are used to collect LiDAR data, and systems are constantly being improved and updated as technology rapidly evolves. A typical aerial or mobile LiDAR system consists of five primary components: a mounting platform, a laser and scanning mirror, an inertial measurement unit (IMU), a global positioning system (GPS) antenna and receiver, and a data collection and processing computer. There are three general categories of platforms: Aerial Laser Scanning (ALS), Mobile Laser Scanning (MLS), and Terrestrial Laser Scanning (TLS). ALS most commonly uses fixed-wing aircraft or helicopters to collect data although blimps and satellite-based systems are also used. MLS 
uses watercraft and land vehicles, such as automobiles, all-terrain vehicles, and snowmobiles. TLS systems are typically mounted on a survey tripod and result in static surveys.

For ALS and MLS systems, the laser is aimed at a scanning mirror, which rotates or oscillates on its center axis, changing the scan angle of the pulses. GPS systems calculate the exact locations of the platform and the laser pulses striking an object or the ground while the scanner measures the angle of the laser pulse. The distance to the target is calculated using a simple formula:

$($ rate $\times$ time $) / 2=$ distance.

The IMU measures platform movements so that roll, pitch, or yaw will not affect the true location of the data. The processing computer records the time and the intensity of the return signals and integrates this information with exact position information calculated from the IMU and GPS data. The distance information for every return pulse is converted to geographic data with $\mathrm{x}, \mathrm{y}, \mathrm{z}$ coordinates that represent latitude, longitude, and elevation (NOAA 2008).

Different LiDAR systems emit laser pulses from different distinct regions of the electromagnetic spectrum. Electromagnetic radiation-charged particles without mass - travels in wave-like patterns. Different types of electromagnetic radiation, such as visible light, microwaves, or radio waves, are characterized by different wavelengths (the length of one complete wave) and frequencies (the number of complete waves that cycle past a fixed point in a given time period). Wavelength and frequency are inversely related; therefore, high-frequency gamma rays $\left(10^{21} \mathrm{~Hz}\right)$ have short wavelengths $\left(10^{-4} \mathrm{~nm}\right)$. Conversely, low-frequency radio waves $\left(10^{7} \mathrm{~Hz}\right)$ have much longer wavelengths $\left(10^{10} \mathrm{~nm}\right)$. LiDAR systems that emit pulses from the infrared (1064 or $1550 \mathrm{~nm}$ ) or visible $(532 \mathrm{~nm})$ portions of the electromagnetic spectrum are most common.

When a laser pulse strikes an object, it may be reflected, absorbed, or scattered, depending on its wavelength and the composition of the object. When laser pulses are reflected in a single direction, the reflection is described as specular. When reflection is specular, the processing computer in a LiDAR system records a single, high-intensity return signal. Intensity is the ratio of the strength of reflected light to emitted light (Chust et al. 
2008). In contrast, absorption occurs when the energy in the pulse is transferred to electrons of the object's surface. When pulses are absorbed, the processing computer records a very low intensity return signal or none at all. Reflection is described as diffuse or scattered when pulses are scattered in many directions after striking a surface. Back scattering sends low-intensity return signals back toward the LiDAR system that generated them.

The type of processor used to record return signals greatly affects the amount of spatial detail in LiDAR data because some processors cannot detect backscattered returns. Older, discrete return LiDAR systems generate data by emitting a pulse from the platform and recording several discrete returns. For example, a pulse travels toward the target surface and is reflected from the first surface it hits, such as the branch in Figure 1. A portion of the energy from the pulse returns to the platform and is recorded as a first return, based on the time it took to return and its intensity. The remainder of the pulse continues through the canopy and hits another branch, and a second return is generated. This process continues until the final surface, the Earth, is reached or the pulse lacks sufficient energy to register a return. However, in complex environments, discrete return systems may not detect all surfaces present. Other LiDAR systems use full waveform LiDAR, also shown in Figure 1. These processors record numerous elevation points for each laser pulse (Mallet et al. 2009). Full waveform LiDAR is particularly well suited for vegetation mapping because it provides a precise reconstruction of the vegetation structure through digitization of the entire backscattered illumination. Because waveform systems digitize the entire returned energy pulse, data collected using these systems provide more spatial detail than data collected using a discrete return system.

The pulse spacing and the size of the laser's footprint on the surface of the Earth also affects the amount of spatial detail in LiDAR data. Landscape features, such as a point bar or a vernal pool, cannot be discerned or measured if they are smaller than the distance between pulses on the ground. Both ALS and TLS use multiple overlapping scans to increase the pulse density, to decrease the distance between pulses on the ground, and to increase the spatial resolution of the data. The amount of spatial detail in LiDAR data is also affected by laser footprint size. The footprint size represents the area of the Earth's surface that is sampled with each pulse. Some ALS systems, such as those on satellite platforms, emit widely 
spaced laser pulses that produce a very large circular footprint, up to 10$25 \mathrm{~m}$ in diameter. Other ALS systems emit more closely spaced, narrower pulses with much smaller footprints, approximately $0.5-1.0 \mathrm{~m}$ in diameter. TLS can emit pulses with a $4.0 \mathrm{~mm}$ laser footprint and a $1.2 \mathrm{~mm}$ pulse spacing over distances up to $50 \mathrm{~m}$ (Hodge et al. 2009b).

Figure 1. Comparison of discrete return and full waveform airborne laser measurements for different target situations. The target is illuminated with a short laser pulse, and when the pulse interacts diffusely with a target, a fraction of the signal is reflected back to the instrument. Multiple surfaces are well characterized using a full waveform system whereas a discrete return system often fails to detect all surfaces in complex or cluttered target environments. (Adapted from Riegl Lasar Measurement Systems [2012].)
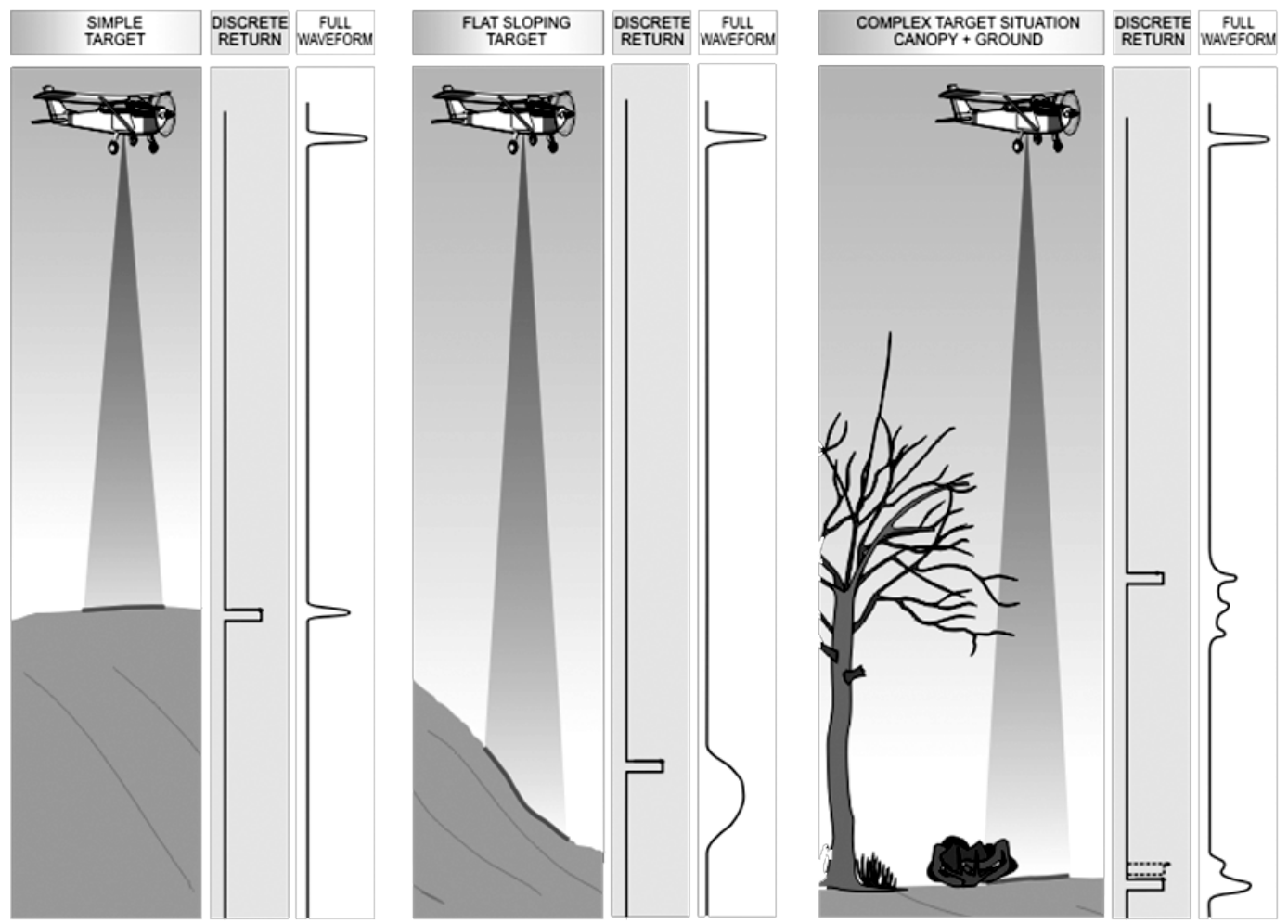

Multiple overlapping scans of the target area reduce line-of-sight limitations and better represent the viewing scene. LiDAR data may be displayed from many points of view, not just from that of the collecting instrument. Areas not visible to the collection instrument, such as the area directly underneath a terrestrial scanner, may leave "holes" in the dataset. Other spots within the collection area where the LiDAR pulse was not able to penetrate or return are known as LiDAR "shadows." The location of these shadows varies with the platform type and the location of the collection instrument. Data collected by aerial platforms may have shadows underneath the roof of a building; data collected using TLS may depict shadows 
extending behind a building. The algorithms used to create models or products out of raw point clouds use different methods to fill or represent areas with low point densities.

Holes in LiDAR data may also result from the pulse wavelength used in a LiDAR survey. Terrestrial ecosystems are commonly surveyed using 1064 or $1550 \mathrm{~nm}$ laser pulses from the near-infrared portion of the electromagnetic spectrum. These longer-wavelength, lower-frequency pulses reflect off terrestrial surfaces, such as buildings or vegetation, producing highintensity return signals. Because near-infrared laser pulses tend to be absorbed or scattered by water, water bodies and inundated wetlands often produce fewer, weaker returns or none at all. These holes and areas of low-intensity returns are used to map water bodies, wetlands, and inundated areas (Brennan and Webster 2006; Chust et al. 2008; Lang and McCarty 2009). However, water bodies may sometimes reflect nearinfrared LiDAR pulses. When water is turbid or when the surface is rough or covered with oil or organic debris, reflection may be specular. In these instances, the return signal intensity is similar to that of terrestrial systems (Milan et al. 2010), so differences among terrestrial systems, water bodies, and wetlands are less apparent. Section 4.3 discusses in greater detail the use of intensity data to map water bodies and wetlands.

Green or bathymetric LiDAR systems provide greater spatial detail in coastal, estuarine, and some riverine ecosystems than do near-infrared or terrestrial LiDAR. These green or bathymetric systems emit shorterwavelength, higher-frequency laser pulses from the blue-green section of the electromagnetic spectrum. Because these $532 \mathrm{~nm}$ pulses are transmitted through standing water to depths of up to $25 \mathrm{~m}$, they generate more spatial detail when the standing water is fairly shallow than does infrared LiDAR. Green LiDAR is used to survey complex benthic habitats, such as coral reefs (USGS 2011). In these systems, pulses reflect off underwater structures, submerged debris, and marine animals and plants, and the underlying substrate produces strong returns (Kinzel et al. 2007; Klemas 2011). Some bathymetric LiDAR systems use green LiDAR pulses in conjunction with near-infrared pulses to produce returns from both the water surface and underwater structures. A combination of infrared and green LiDAR is also used to map snow depth (Deems et al. 2013), a significant water source for ephemeral and intermittent streams in many USACE regions. Older, high-energy green LiDAR systems caused eye damage 
(Milan et al. 2010), but newer systems require less energy per pulse and are considered eye safe at specified distances (USGS 2011).

\subsection{Processing LiDAR data: point clouds, models, and LiDAR-derived products}

The $x, y$, and $z$ location data from all return signals form a cloud of points that represents the surface of the Earth and the objects on it at a particular location. Each point is also associated with the intensity value for that return. Raw LiDAR data are processed to remove points thought to represent outliers or erroneous data, created by birds, planes, marine mammals, certain reflective surfaces, or false ground points produced by low vegetative cover. Holes in the data, created by scanner locations or water bodies, may also be filled in at this time. Processed LiDAR data are represented as three-dimensional point clouds. Subsections of the original point cloud created by filtering are used to create Digital Terrain Models (DTMs) or Digital Surface Models (DSMs) after further processing. Algorithms are used to filter or classify points into subsections based on return type (e.g., the first or the last returns). When three-dimensional LiDAR models are processed even further and are represented in two dimensions, they are described as LIDAR-derived products. Products are available in both vector (contour lines) and raster format (Digital Elevation Models [DEMs]). Secondary products, such as Topographic Wetness Indices (TWI), use LiDAR-derived products, such as a DEM, to calculate values for other variables that were not directly measured by the LiDAR system. Point clouds, models, LiDAR-derived products, and secondary products may be useful to investigators during OHWM or wetland delineations.

Point clouds contain more spatial detail than models and products, so they may be the most useful for delineation purposes. Processed point clouds are downloaded in ASCII or LAS (Log ASCII Standard) formats or as a compressed LAZ file. These files are most easily imported, displayed, and measured using LiDAR software, such as Quick Terrain Reader 7.1.6 (Applied Imagery 2012). This program can handle models composed of up to 200 million points and point-cloud data composed of up to 100 million points. Differences in elevation or return intensity are typically displayed using different colors and can be measured and evaluated. Although more difficult to use, some GIS have specialized toolbars that enable them to display and evaluate LiDAR data in three dimensions. The LAS dataset toolbar, a software extension for ArcMap 10.1, is one example. One drawback to working with point clouds is that they require considerable storage 
space because they are three dimensional and consist of millions of data points. For example, the processed point cloud in Figure 2, collected by the National Aeronautics and Space Administration's Airborne Topographic Mapper and a waveform digitizer, consists of 442,977 points and requires $8,364 \mathrm{kB}$ of space. Datasets collected using TLS may be even larger. The unprocessed point cloud in Figure 3b, collected using a terrestrial platform and a waveform digitizer, consists of $5,780,445$ points and requires $144,526 \mathrm{kB}$ of space.

Figure 2. Point cloud from Mission Creek, $\mathrm{CA},{ }^{*}$ collected using an aerial platform and a waveform digitizer, the National Aeronautics and Space Administration's Airborne Topographic Mapper. In the legend, elevation is measured in meters. The point cloud is displayed using Quick Terrain Reader 7.1.6 (Applied Imagery 2012).

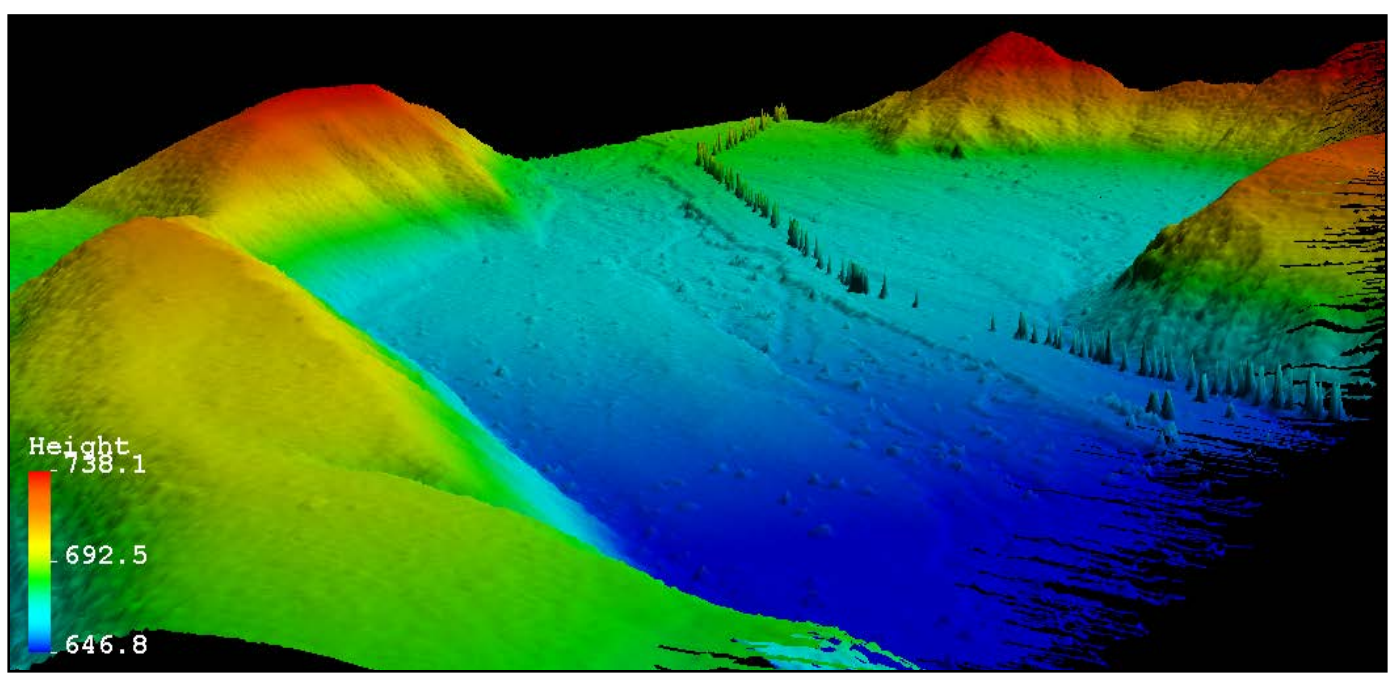

LiDAR models, such as DTMs and DSMs, are three-dimensional subsets of the original point cloud, which will also be useful for delineating OHWM boundaries and wetlands. Model creation involves classifying the points in a data cloud into groups, such as first returns, last returns, etc. Specialized algorithms select one group of points to model, such as those representing the last return. Models consisting of the lowest points in a data cloud, known as DTMs, are commonly used to map topography as these lowest points are thought to represent only the Earth's surface. Unless specified as a bathymetric model, DTMs map only the top surface of water bodies, excluding underwater terrain. The DTM in Figure 3a displays the height of only the Earth's surface, contains about one quarter of the points, and requires one quarter of the storage space used by the original point cloud (Figure 3b), which displays the heights of vegetation and other objects in addition to the Earth's surface.

* D. Finnegan, unpublished LiDAR data. USACE ERDC-CRREL, 2006. 
Figure 3. Comparison of (a) a 37,706 kB DTM (1,509,218 points) and (b) a 144,526-kB point cloud $(5,780,445$ points). Both images were produced from the same data collected from a terrestrial platform with a waveform digitizer in Ascutney, VT. * The data are colorized by elevation. The legends are displayed in meters. The data are displayed using Quick Terrain Reader 7.1.6 (Applied Imagery 2012).
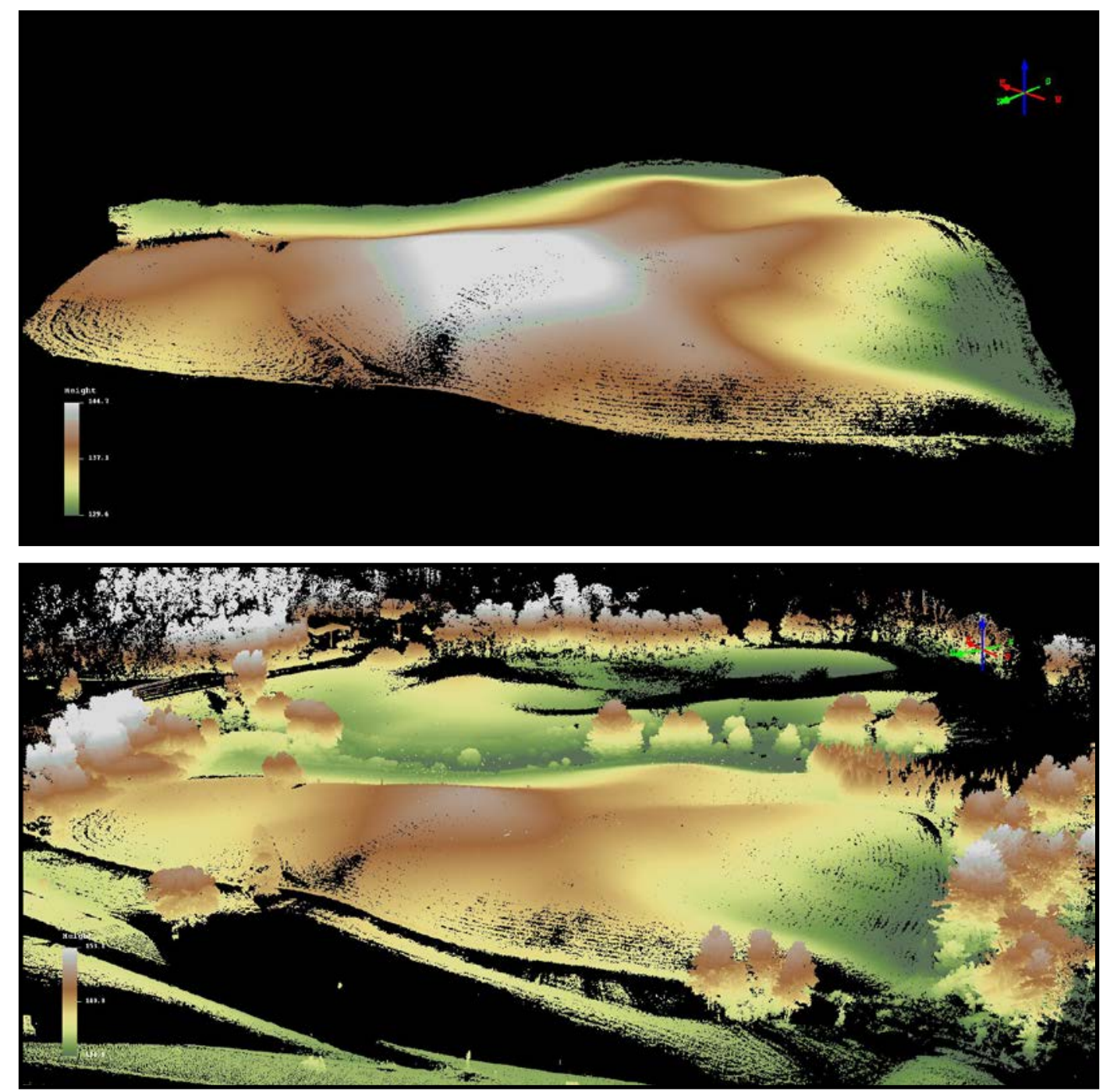

DSMs represent different subsets of the original point cloud and are created in one of two ways. The first method uses a specialized algorithm to subtract the last return from the rest of the LiDAR point cloud, leaving a profile of the vegetation. An alternative method for creating a DSM is to remove from a LiDAR point cloud all points except for the first returns so that the data represent the heights of the top of the vegetation layer. Reutebuch et al. (2003) provide examples of DSMs and DTMs created from a LiDAR survey of a conifer forest. LiDAR models are available in the same type of files as point clouds and are viewed using the same software.

${ }^{1}$ D. Finnegan and A. LeWinter, unpublished LiDAR data. USACE ERDC-CRREL, 2012 
One potential drawback to working with models is that they contain fewer data than point clouds, so much spatial information is lost. Loss of information may or may not be problematic, depending on the investigator's objective. For example, if the sole objective is to identify geomorphic breaks in slope associated with the OHWM, points representing vegetation are of little importance.

LiDAR-derived products may also be useful for regulatory purposes. These two-dimensional products are created from three-dimensional DTMs and DSMs after still further processing. LiDAR-derived products are displayed in vector or raster geographic representations, sometimes after being combined with other types of data. Vector representations, such as highresolution contour lines and Triangulated Irregular Networks (TINs), may be downloaded in many formats, including geodatabases or shapefiles. Contour lines, derived from DTMs, consist of a series of isobars that represent fairly small changes in elevation. These two-dimensional representations of the last returns of a LiDAR point cloud provide less spatial information than a DTM but require far less storage space. For example, the $1.0 \mathrm{~m}$ LiDAR-derived contour lines (represented as black isobars) in Figure 6a require $856 \mathrm{kB}$ of space (Nayegandhi et al. 2010). Because contour lines are created from many sources, users should check metadata to ensure that their file was created from LiDAR data.

TINs are a second type of vector representation that can be derived from DTMs or DSMs and may be useful for delineation purposes. TINs use points, lines, and triangles to model objects and the Earth's surface. TINs are created by drawing lines to connect three adjacent points in a model, transforming it into a network of adjacent triangles that do not overlap. Variables, such as height or return intensity, are assumed to vary linearly within the triangles. The density and size of the triangles can be adjusted to better represent heterogeneous areas in the landscape. TINs are particularly useful for representing surfaces or for displaying streams, ridges, and peaks in the landscape because they add perspective to the visualization capabilities of the GIS and contain precise coordinates. Unlike point clouds, TINs are not three-dimensional data although they take on a threedimensional appearance when select triangles are shaded or an aerial photograph is overlain. Often, data from another source are added to LiDAR-derived TINs. These data may be linear features, such as contour lines from a topographic map; wetland or stream boundaries from geographically referenced aerial photographs; or data from a field survey, 
such as thalweg measurements. LiDAR-derived TINs enhanced with hydro-breaklines created from field surveys of stream cross sections are often used to model stream flow or erosion in channels (Perroy et al. 2010). This type of LiDAR-derived product could be extremely useful for OHWM delineations. Whenever a TIN is used for delineation purposes, it is important to determine all sources of data used to produce it. Although some TINs are created from LiDAR data, others are constructed from geographically referenced aerial photographs, the contour lines of topographic maps, or data from field surveys. The literature suggests that TINs created from LiDAR data are better able to model discharge and the elevation of the water surface and to delineate flooded areas than are TINs made from other sources. LiDAR-derived TINs are also more sensitive to changes in Manning's roughness coefficient (Casas et al. 2006).

Other LiDAR-derived products, represented in raster format, may also be useful for delineation purposes. Raster images display continuous variables across a landscape, such as changes in elevation or intensity. The format is similar to a digital photograph in that it is composed of a regular grid of small cells or pixels, which are usually square. Each pixel in the image represents an equivalent portion of the study area, such as $1.0 \mathrm{~m}^{2}$. Elevation or intensity values are assigned to each pixel based on the returns from its area. Algorithms are used to predict values for areas where explicit LiDAR returns do not exist (e.g., areas of shadow or low intensity). Raster products are available in many file types, including but not limited to TIFF, ASC, IMG, and KML files or compressed as a KMZ file. These files are quickly imported and viewed using GIS such as Google Earth Pro (Terra Metrics 2010) or Global Mapper 13.0 (Blue Marble Geographics 2012). Both programs can be operated by users without extensive background in GIS. Because raster images are two-dimensional representations of threedimensional LiDAR models, they provide less spatial information than the model itself, but they often require less storage space. For example, the $1.0 \mathrm{~m}$ bare earth DEM represented as a colored gradient in Figure 6a requires 15,690 kB of space (Nayegandhi et al. 2010).

Three types of rasters derived from LiDAR models may be useful for delineation purposes: DEMs, canopy height models (CHMs), and secondary products. Bare-earth DEMs, which display the height of the Earth's surface, are two-dimensional representations of DTMs. Color gradients are used to illustrate differences in elevation or return intensity among pixels. See the previously mentioned example in Figure 6a (Nayegandhi et al. 
2010). Investigators should examine metadata to determine if a DEM was derived from LiDAR data as DEMs can be constructed from many sources, including GPS surveys, geographically referenced aerial photographs, and topographic maps (Figure 4a). The literature suggests that for mapping wetlands and for assessing and modeling hydrologic variables, such as watershed area, connectivity and continuity of drainage networks, watershed elevation, and slope, LiDAR-derived DEMs are better than DEMs derived from topographic maps or from aerial photography (Hopkinson et al. 2009). Likewise, DEMs created from LiDAR data are better able to model and predict the presence of wetlands and uplands (Hogg and Holland 2008) and better able to model relationships between vegetation and elevation (Moeslund et al. 2011) than DEMs created from other sources.

CHMs or canopy altitude models (CAMs) are a second type of LiDARderived product distributed in raster format. These two-dimensional products use first returns from a LiDAR point cloud to classify vegetation into categories. Common categories include trees, tall shrubs, short shrubs, broad-leaf herbaceous vegetation, grasses, and aquatic vegetation (Hopkinson et al. 2004; Farid et al. 2006; Bork and Su 2007). For an example, see Nayegandhi et al. (2010) in Figure 6b. These LiDAR-derived products are often fused with other types of remote sensing data, such as multispectral or hyperspectral imagery, to improve classification accuracy. Multispectral imagery uses broad band frequencies in the visible light range (i.e., red, green, and blue bands) and in the near-infrared range to capture image data at high (less than $1.0 \mathrm{~m}$ ) spatial resolution (aerial platforms) or lower (several meters) spatial resolution (satellite platforms). LiDAR data are often collected in conjunction with multispectral images (Lichvar et al. 2006; Anderson et al. 2010). Fusing multispectral imagery with LiDAR data improves the overall classification accuracy of floodplain vegetation (Geerling et al. 2007) and wetlands (Chust et al. 2008; J enkins and Frazier 2010) by as much as $40.0 \%$. A second type of remotely sensed data-hyperspectral imagery - captures image data at narrow band frequencies across the electromagnetic spectrum, including near-infrared, shortwave infrared, and visible light, at a high spatial resolution. Fusions of hyperspectral imagery and LiDAR data improved the overall classification accuracy of wetland graminoids by $11.0 \%$ (Onojeghuo and Blackburn 2011).

Investigators may also find useful for delineation purposes secondary products or indices that are derived from LiDAR data and displayed in 
raster format. Secondary products use LiDAR-derived products, such as the topographic data in a bare-earth DEM, to calculate values for variables that were not directly measured by the LiDAR sensor. Soil wetness indices, which predict the degree of moisture in the soil from watershed area and slope, are one example that investigators may find useful. Other examples of secondary products derived from LiDAR products include slope, curvature, aspect (Shaeffer 2008), lagg width, lateral slope, and peatland topographic indices (Richardson et al. 2010). These indices are discussed in greater detail in Section 4.3.

\subsection{Metrics for evaluating LiDAR data}

Before using LiDAR data in delineations, investigators should examine the metadata to ensure that the data are adequate for regulatory purposes. High-resolution data are strongly recommended although the term "highresolution" becomes relative as LiDAR technologies evolve and the spatial resolution of the data increases. Regardless, spatial resolution is extremely important for regulatory purposes because it determines the features that can be discerned; the smallest length or height that can be accurately measured; and most importantly, the conclusions that can be drawn from a dataset. The amount of spatial detail in point clouds and LiDAR-derived products is described using the concepts of point spacing, horizontal resolution, and vertical accuracy.

The degree of spatial detail in an unprocessed LiDAR point cloud is quantified using two metrics: point density and point spacing. Point density refers to the spacing of the return signals recorded per unit area (e.g., 6 points $/ \mathrm{m}^{2}$ ). Point spacing describes the number of return signals recorded in a given unit of length (e.g., 1 point/ $\mathrm{m}$ ). ALS can produce data clouds with point densities ranging from 4 to 12 points/ $\mathrm{m}^{2}$ (Lang and McCarty 2009; Frazier et al. 2012). TLS datasets contain more spatial detail and more points than data collected using ALS. For example, Milan et al. (2010) used TLS to collect two point clouds with densities of 1300 and 2528 points $/ \mathrm{m}^{2}$.

Likewise, the degree of spatial detail in processed point clouds, DTMs, and DSMs is quantified using post density (points $/ \mathrm{m}^{2}$ ) and post spacing (points/m). The horizontal resolution of a LiDAR model, such as a DTM, is typically lower than that of the point cloud it was created from because data are removed during model creation. For example, a point cloud of 37 million points collected in an upland conifer forest had an initial point 
density of 4.2 points $/ \mathrm{m}^{2}$. After points representing vegetation were filtered out, 4 million bare-earth points remained. The post density of the DTM was 0.58 points $/ \mathrm{m}^{2}$, and the post spacing was $1.3 \mathrm{~m}$ (Reutebuch et al. 2003). Because more data are collected using TLS, more points are retained after processing. In a riparian substrate study, point clouds that initially contained 35 and 54 points/ $\mathrm{cm}^{2}$ prior to filtering had post densities of 17 and 30 points $/ \mathrm{cm}^{2}$, respectively, after processing (Hodge et al. 2009a).

The horizontal resolution of a LiDAR-derived DEM is most commonly stated as the length that a pixel side actually represents (e.g., $1.0 \mathrm{~m}$ ). The horizontal resolution of a LiDAR-derived product is lower than that of the original point cloud or model because many points are averaged or interpolated to create the product, so that groups of points represent planar surfaces or pixels. For instance, the previously described data cloud from the conifer forest with the post spacing of $1.3 \mathrm{~m}$ was processed further to create a $1.52 \mathrm{~m}$ DEM (Reutebuch et al. 2003). In the riparian substrate study, point clouds with post densities of 17 and 30 points/ $\mathrm{cm}^{2}$ were further processed to create $1.0 \mathrm{~mm}$ DEMs.

Because LiDAR data and products are representations of $\mathrm{x}, \mathrm{y}$, and $\mathrm{z}$ coordinates, their horizontal resolution determines how well landscape features are represented. If the distance between points is less than the length of the feature, then it can be discerned and measured. For instance, a terrain feature that is $2.0 \mathrm{~m}$ in length, such as a sloping channel bank or gravel bar, could be discerned and measured using a LiDAR point cloud with point density of 4.2 points/ $\mathrm{m}^{2}$, a DTM with a post spacing of 1.3 points/ $\mathrm{m}$, or a LiDAR-derived $1.52 \mathrm{~m}$ DEM because, in all three cases, the distance between points or the horizontal resolution is less than the length of the feature. However, none of these could measure an abrupt break in slope $0.3 \mathrm{~m}$ in length, regardless of its height.

The high horizontal resolution of LiDAR data and products clearly provides an advantage over the topographic data that traditionally have been available for preliminary delineations, such as $10 \mathrm{~m}$ resolution DEMs available from the National Elevation Dataset (NED) (Gesch 2007). Because many features that affect watershed drainage are less than $10 \mathrm{~m}$ in length (NOAA 2008), lower-resolution data are less useful for OHWM determinations and wetland delineations because they cannot accurately represent these small features. To illustrate, compare two floodplain maps 
of the Humboldt River Valley in northwestern Nevada. In Figure 4a, a $10 \mathrm{~m}$ DEM from NED (http://nationalmap.gov/) is used to model the active channel and the surrounding floodplain. The $10 \mathrm{~m}$ DEM shows an extremely sinuous, 30 to $40 \mathrm{~m}$ wide channel with one small tributary. The widest portion of the channel, at the southwestern end, is $83 \mathrm{~m}$ across. The floodplain also appears to be quite wide, ranging from $185 \mathrm{~m}$ in the northeast to $1016 \mathrm{~m}$ in the southwest. In Figure 4b, the same area is represented in two dimensions using a $1.0 \mathrm{~m}$ resolution LiDAR-derived DEM, collected by the National Center for Airborne Laser Mapping (NCALM) (http://ncalm.org). In this figure, the channel appears much thinner, about 20$25 \mathrm{~m}$ wide in the northeast and $62.5 \mathrm{~m}$ wide at the southwestern end. In addition, these data suggest different channel morphologies; the main flow path appears much less sinuous in the $1.0 \mathrm{~m}$ LiDAR data than in the $10 \mathrm{~m}$ DEM. Also, a number of tributaries that cannot be discerned in the $10 \mathrm{~m}$ image are apparent in the LiDAR image. Certainly horizontal resolution is one explanation for these differences. However, differences could also be temporal as channel morphology can change over time. The LiDAR data were collected in 2010 while the NED data were digitized in 2001 from a 1972 7.5-minute topographic map. Sections 3 and 4 discuss in more detail the importance of acknowledging the temporal resolution of LiDAR data. 
Figure 4. Comparison of two floodplain maps of the Humboldt River Valley in northwestern NV.

a. $10.0 \mathrm{~m}$ resolution DEM was digitized in 2001 from a 7.5-minute topographic map published by the USGS in 1972. The DEM was obtained from the National Elevation Dataset (Gesch 2007) and is displayed using ArcMap 10.1 (ESRI 2011).

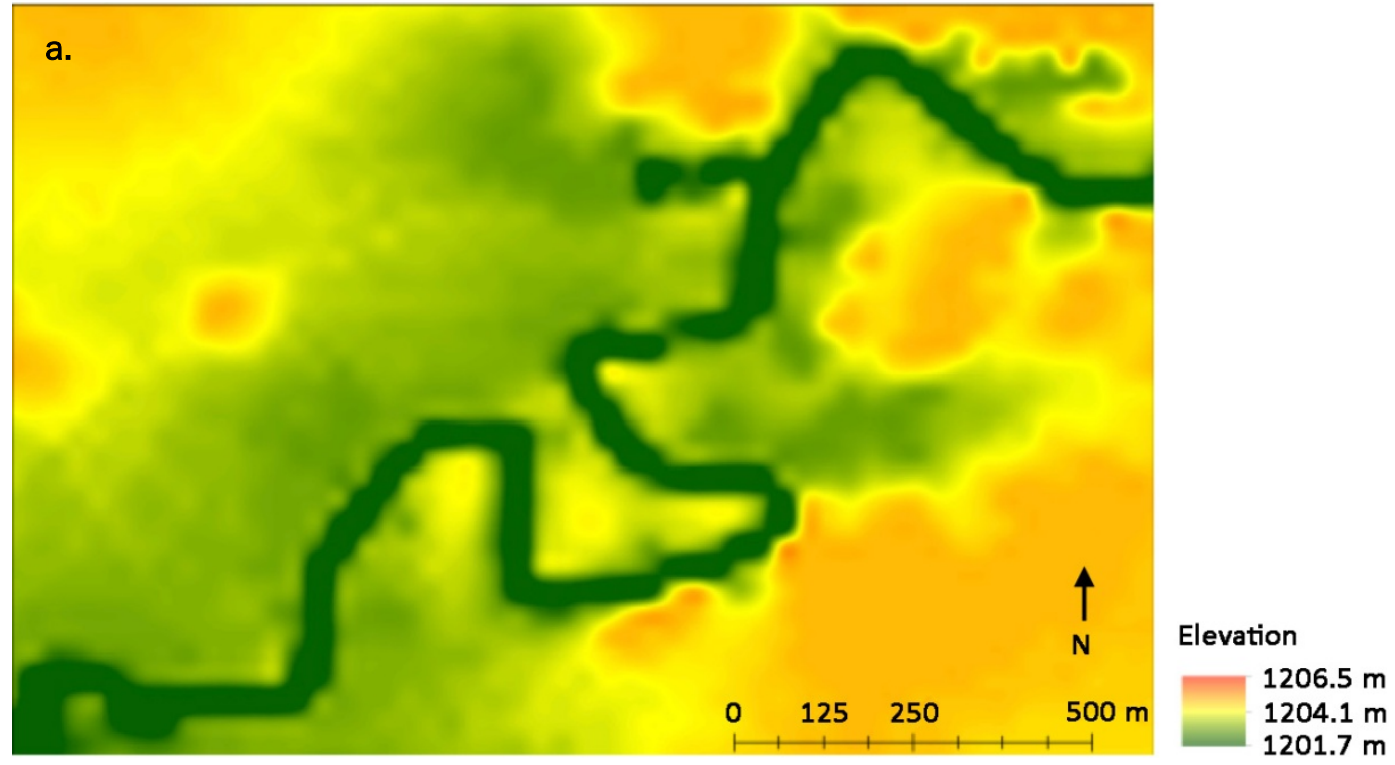

b. $1.0 \mathrm{~m}$ LiDAR point cloud collected by the National Center for Airborne Laser Mapping (DOI: 10.5069/G98G8HMJ) on 7 August 2010. The point cloud was obtained from the OpenTopography Facility (2011). It is displayed in two dimensions using Quick Terrain Reader (Applied Imagery 2012).

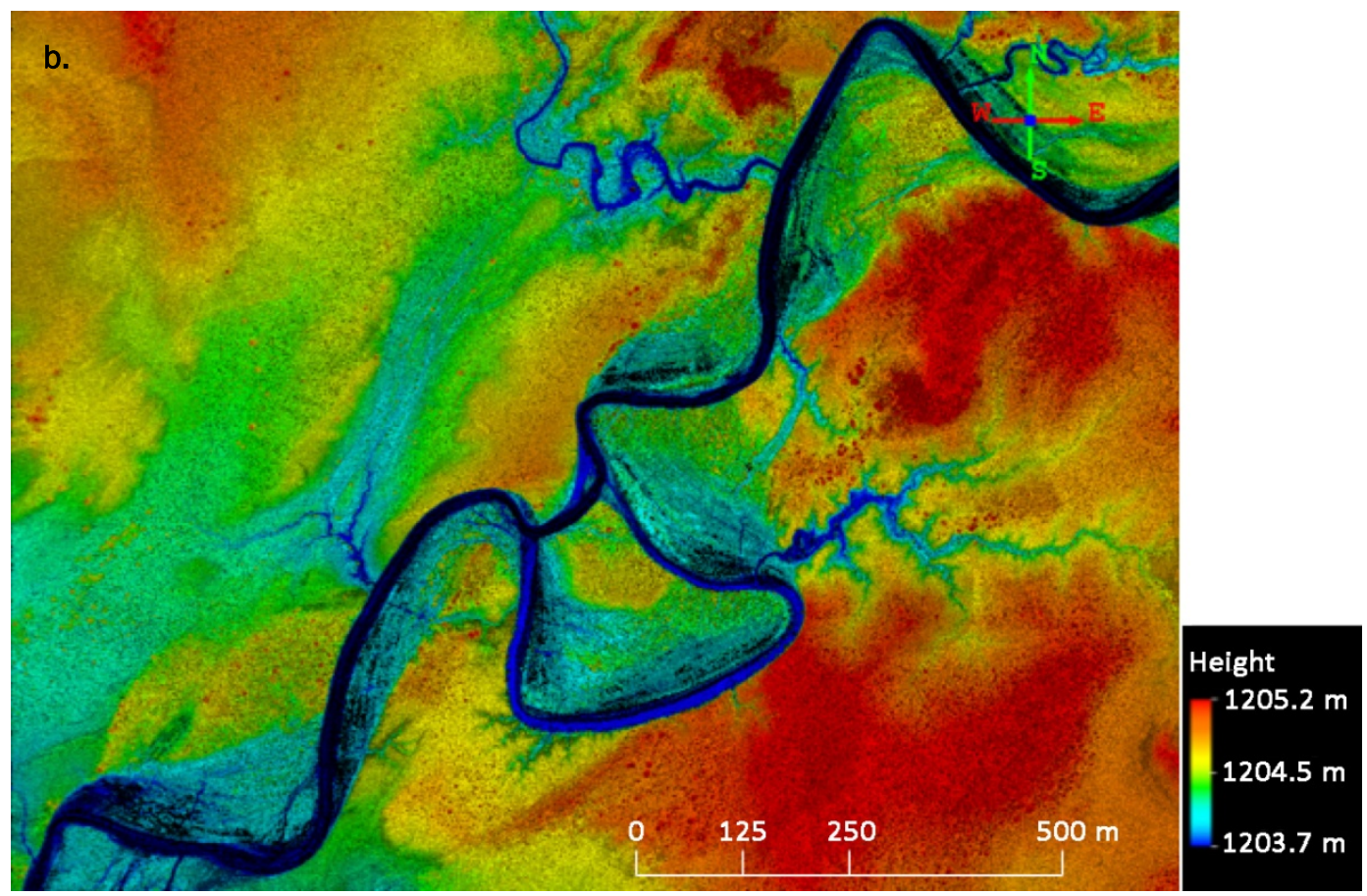


Vertical accuracy also limits the conclusions that can be drawn from LiDAR data or products. Most often, vertical accuracy is determined by ground truthing. The elevation of bare-earth points is remeasured using a different method, such as a differential GPS device. At each point, the LiDAR-derived elevations are compared to the GPS-derived elevations. Sometimes, other methods, such as gauge data in riparian systems (Hall et al. 2009) or image interpretation-based point counting in inaccessible terrain (J enkins and Frazier 2010), are used to check the vertical accuracy of LiDAR data. Two metrics-root mean square error (RMSE) and fundamental vertical accuracy (FVA) - are used to quantify vertical resolution (NOAA 2008; USGS 2010). The RMSE represents the squared average difference between the elevations measured using LiDAR and the elevations measured using another technique, such as GPS. It is similar to one standard deviation. The FVA represents a 95\% probability that the accuracy of a bare earth point will be greater than or equal to a specific value. The FVA is calculated by multiplying the RMSE by 1.96. It is similar to two standard deviations. For example, one TLS-derived DEM of western canyons reported an RMSE of $0.025 \mathrm{~m}$ and an FVA of $0.049 \mathrm{~m}$ (Perroy et al. 2010). When the height of a feature is less than the FVA, it cannot be measured accurately. For instance, neither the height nor the length of large woody debris in riverine systems could be accurately measured with a $1.0 \mathrm{~m}$ resolution LiDAR-derived DEM with a vertical accuracy of $0.50 \mathrm{~m}$ (Frazier et al. 2012). It is important to note that, for two reasons, the horizontal accuracy of LiDAR data is generally treated as a function of vertical accuracy. First, horizontal accuracy is difficult to ground truth and evaluate, particularly in areas with few planimetric surfaces. Second, the horizontal accuracy must be high to achieve high vertical accuracy (NDEP 2004).

If LiDAR data have not been ground truthed, the metadata usually contain a statement of the vertical accuracy from the manufacturer of the LiDAR system. However, the accuracy of the LiDAR scanner itself may not always reflect the true accuracy of the processed data, which also must incorporate, for example, the accuracies of the IMU and the GPS. The Universal LiDAR Error Model (ULEM) is a type of metadata that calculates LiDAR accuracies by propagating system-specific measurement errors through the derivation of $\mathrm{x}, \mathrm{y}$, and $\mathrm{z}$ values from the raw sensor data. It is not yet in widespread use, but it indicates that the ability to quantify the accuracy of LiDAR data is an area of active research and that methods can be expected to improve. 
In addition to evaluation of the spatial resolution, the classification accuracy of land cover or vegetation classes in LiDAR-derived products, such as DEMs or CHMs, is quantified on a scale of $0 \%$ to $100 \%$ by using three metrics: user's accuracy (UA), producer's accuracy (PA), and/ or overall accuracy (OA). Whenever possible, in this review these metrics are presented together in the following form: UA/PA. UA quantifies how well each pixel in the product represents the field conditions in the corresponding area. For example, in a floodplain vegetation classification study by Geerling et al. (2007), 13 pixels were classified as dominated by Bromus inermis (smooth brome) and Eryngium campestre (field eryngo). Four of the 13 corresponding field validation plots were actually dominated by these plants. In this case, $\mathrm{UA}=(4 / 13) \times 100=31 \%$ for the $\mathrm{B}$. inermis $\mathrm{E}$. campestre vegetation category. In contrast, PA describes how well the product classifies each pixel. Using the same example, 53 field validation plots were dominated by the B. inermis/E. campestre vegetation category. J ust 4 of the corresponding 53 pixels in the product were classified as such. The PA $=(4 / 53) \times 100=8 \%$ for this category. Finally, the OA of $37.0 \%$ reported by Geerling et al. (2007) represents the combined accuracy of all eight vegetation categories in their classification system.

\subsection{Current federal LiDAR guidelines}

Because LiDAR technology is still developing, few standards have been set for data collection. As of this printing, the US Army Corps of Engineers (USACE) has no standards or requirements for LiDAR data collection or processing. In December 2011, USACE formed a LiDAR Community of Practice (COP) (Finnegan 2012). USACE standards for data collection and processing are forthcoming. The standards and specifications developed by the LiDAR COP will take precedence over the information in the following paragraphs. Until then, we recommend adherence to the minimum guidelines and specifications published by the US Geological Survey (USGS 2010) and the Federal Emergency Management Agency (FEMA 2010). These minimum specifications guide data collection and the use of LiDAR data for NED and flood hazard mapping. Although specifications from the Federal Geographic Data Committee (FGDC) Wetlands Subcommittee permit wetland mapping using LiDAR data, these minimum specifications for geographic data were not developed specifically for LiDAR data, so they do not specify requirements for point spacing or vertical accuracy (FGDC 2009). 
Investigators should examine the spatial resolution of LiDAR data and products to ensure that these metrics meet USGS and FEMA minimum specifications. If LiDAR data are to be included in NED, unprocessed point-cloud data must have a nominal pulse spacing of one point every 1.0-2.0 m. The horizontal resolution of LiDAR-derived DEMs should be $3.0 \mathrm{~m}$ or less (USGS 2010). FEMA requires the same post spacing in flat floodplains characterized by high flood risk although values as low as one point every $5.0 \mathrm{~m}$ are acceptable in low-risk, hilly terrain (FEMA 2010). As of 2012, a post spacing of one point every $0.5 \mathrm{~m}$ in point-cloud data is common and considered repeatable (Finnegan 2012). Post spacing as high as one point every $0.35 \mathrm{~m}$ has been reported from airborne systems (Lang and McCarty 2009). Point clouds from TLS can have a post spacing as high as one point every 1.2-2.0 mm (Hodge et al. 2009b) although spacing depends on the distance from the scanner. Areas closest to the scanner have the closest point spacing. The literature suggests that LiDAR-derived products made from data collected by ALS commonly have horizontal resolutions of $1.0 \mathrm{~m}$ (Hall et al. 2009; Maxa and Bolstad 2009; J enkins and Frazier 2010; Frazier et al. 2012). Horizontal resolutions of products created from TLS can be as low as $1.0 \mathrm{~mm}$ (Hodge et al. 2009b) or $0.25 \mathrm{~m}$ (Perroy et al. 2010).

Investigators should also check the reported vertical accuracy estimate for each dataset to ensure that it meets current USGS or FEMA guidelines. Although the wetlands subcommittee of the FGDC currently has no standard for vertical accuracy, the USGS requires a vertical accuracy of $24.5 \mathrm{~cm}$ at the 95\% confidence level for LiDAR products included in NED (USGS 2010). FEMA's specifications for mapping high-risk, flat floodplains require the same vertical accuracy although vertical accuracies of $147 \mathrm{~cm}$ are acceptable in hilly areas with low risk of flooding (FEMA 2010). The literature suggests that vertical accuracies of $15.0 \mathrm{~cm}$ are common and are considered repeatable (Lang and McCarty 2009; Zhao et al. 2010). However, reported vertical accuracies may be as high as $1.3 \mathrm{~mm}$ for data collected by TLS (Hodge et al. 2009b) or as low as $0.63 \mathrm{~m}(\mathrm{RMSE}=0.32 \mathrm{~m}$ ) for older datasets or for data collected in dense vegetation, such as conifer forests (Reutebuch et al. 2003).

With regard to classification accuracy, the wetlands subcommittee of the FGDC recommends a PA of $98 \%$ for the correct identification of wetlands vs. nonwetlands when wetland size is at least 0.2 ha ( 0.5 acres). A PA of $85 \%$ is recommended for attribute accuracy, meaning that the wetland was 
classified as the correct type, such as PFO4B (palustrine, forested, needleleaved evergreen, saturated), using the FGDC Wetlands Classification Standard. At this time, there are no requirements for UA (FGDC 2009).

\subsection{Recommendations}

LiDAR technology is constantly being upgraded and refined, ever enhancing our ability to view the Earth at larger and larger scales. Although LiDAR may accurately represent coarser-grained features, such as channel morphology, it may not capture all of the fine-grained features, such as some changes in sediment texture. Because the field is still evolving, there are few guidelines or standards regulating data collection and processing. Therefore, the following recommendations are made with the understanding that any guidelines developed by USACE's newly formed LiDAR COP will take precedence. For now, investigators should make sure that the data meet or exceed the minimum federal specifications described by FEMA (2010) and the USGS (2010). High-resolution data are recommended for preliminary OHWM and wetland delineations although the term "high resolution" will be defined differently as LiDAR technology continues to develop. As of 2014, TLS datasets often provide the highest spatial resolution and will be most useful for delineation purposes, with one exception. Perroy et al. (2010) found that ALS produces more accurate results than TLS in steeply sloped, deeply incised, first-order streams. Low, slow-flying aircraft and slow-moving vehicles also collect highresolution LiDAR data. Future technological advances will likely result in the collection of high-resolution data, regardless of platform type. 


\section{Using LiDAR Data in Preliminary OHWM Delineations}

During a preliminary delineation, remote sensing resources, including satellite imagery, aerial photographs, soil maps, vegetation maps, geology maps, or rainfall data, may be used to approximate the signature of the OHWM across the landscape (Lichvar and McColley 2008). The literature suggests that LiDAR data are another remote sensing resource that may be useful, provided that investigators are cognizant of the channel discharge history. Once relationships between discharge history and LiDAR survey dates have been determined, LiDAR data and products can be used during preliminary delineations of the OHWM boundary to discern patterns in vegetation density and some breaks in slope across the landscape. LiDAR is less useful, however, for documenting changes in sediment texture.

Before LiDAR data can be used during preliminary delineations of the OHWM boundary, the data collection date should be considered in the context of discharge history because the vegetation patterns and channel morphology are a reflection of the recent flow patterns. Vegetation is often absent from a stream channel immediately after a moderate to large event, but it may reestablish within the active channel during extended periods of low flows. Likewise, the active channel boundary tends to remain stable for low to moderate discharge events but may shift after a large flood event. Thus, understanding the discharge history is critical to interpreting the LiDAR data. Metadata contain a table showing the date and location of each survey or flight. Data collected prior to a large flood event, such as those generated by tropical storms or hurricanes, may be less useful because these events are capable of altering the channel morphology. Data collected after years of low flows need to be scrutinized more closely because vegetation patterns may hide the physical channel features.

LiDAR data collected prior to the most recent flood or ordinary flow event should be used with caution because channel morphology and the locations of OHWM indicators may have changed since the data were collected. 
Figure 4 suggests that the channel morphology of the Humboldt River in northwestern Nevada changed between 1972 (Fig. 4a) and 2010 (Fig. 4b). The sinuous, winding section of the active channel mapped in 1972 appears to be a high flow channel in 2010. However, it is important to note that some of these morphological differences, such as the presence of small tributaries, are attributable to differences in the horizontal resolution of the data ( $10 \mathrm{~m}$ vs. $1.0 \mathrm{~m}$ ). This type of comparison can sometimes be useful for determining channel stability, particularly whether or not a channel might return to pre-flood conditions after a large flood event. LiDAR data collected before a flood event can also be used to map physical features located above the active channel, such as mature vegetation or a terrace (abandoned floodplain) boundary. LiDAR-derived maps showing the positions of these terrace indicators may help an investigator focus the field investigation by distinguishing the outer limit of potential OHWM locations.

\subsection{Mapping vegetation patterns}

Once relationships between discharge history and survey dates have been determined, LiDAR data or products can be used to map an estimated boundary of the OHWM by using the landscape-level signature created by a combination of three indicators: changes in vegetation density, breaks in slope, and changes in sediment texture. The literature suggests that LiDAR topographic data alone are unable to accurately classify and map vegetation (Geerling et al. 2007; Anderson et al. 2010). However, CAMs or CHMs created from LiDAR point clouds and used in combination with another remote sensing resource can be used to map patterns among vegetation units based on height. In some instances, plant communities on terraces (abandoned floodplains) may be the most mature and the densest as succession is not set back by the stochastic disturbance of flood events (Curtis et al. 2011). LiDAR data can be used to map these communities, and communities of tall shrubs, that can become established either in the floodplain or in active channels characterized by a high water table. For instance, a $0.5 \mathrm{~m}$ resolution CAM that incorporated topographic data and return intensity distinguished among young (less than 15 years), mature (16- 50 years), and old (greater than 50 years) stands of Populus deltoides ssp. fremontii (= Populus fremontii) (cottonwood) growing along the San Pedro River in southeast Arizona (Farid et al. 2006). Classification accuracy varied with stand age. Most of the old-stand validation plots were classified correctly $(\mathrm{PA}=89 \%)$, but the likelihood of a pixel representing actual field conditions was quite low ( $\mathrm{UA}=38 \%$ ). The reverse was true of young 
stands, which had UA/PAs of 100\%/41\%. Mature stands were represented most accurately, with UA/PAs of 78\%/ 73\%. This research suggests that changes in canopy height or return intensity do not always correspond to stand growth form. Therefore, any changes in stand growth form suggested by LiDAR data must be verified in the field.

Other research suggests that LiDAR data accurately classify tall plants, such as trees and shrubs, but are much less accurate when distinguishing among smaller plants and bare earth. Forested communities were well classified using a $2.0 \mathrm{~m} \mathrm{LiDAR-derived} \mathrm{CHM} \mathrm{with} \mathrm{a} \mathrm{vertical} \mathrm{accuracy} \mathrm{of}$ $0.07 \mathrm{~m}$ (Geerling et al. 2007). Almost all of the validation plots in riparian forests were classified correctly (PA $=97 \%$ ), and there was a $100 \%$ probability that pixels classified as forest represented actual field conditions. Communities of tall shrubs, such as Sambucus nigra (black elder), were also well classified with UA/ PAs of 94\%/84\%. However, the overall classification accuracy dropped to just $41 \%$ when five broad vegetation classes were considered, including bare ground, grasses and herbs, herbs and low shrubs, tall shrubs, and forest (Geerling et al. 2007). One reason that LiDAR has difficulty distinguishing among smaller plants is that height differences among herbaceous plants and low shrubs are sometimes not significant (Hopkinson et al. 2004). For example, a 3 m resolution CHM with a vertical accuracy of $0.10 \mathrm{~m}$ could not distinguish herbaceous plant communities from Artemisia arbuscula (dwarf sagebrush) communities in the Arid West region (Sankey and Bond 2011). However, height differences measured in field validation plots were not significantly different either.

A second reason that grasses, herbs, and small shrubs are poorly represented in LiDAR-derived products is because the data consistently underestimate the height of the canopy. Although LiDAR data underestimate the height of all vegetation, the relative vertical error is greatest for small plants and aquatic vegetation (Hopkinson et al. 2004). There are several explanations for this underestimation (Hopkinson et al. 2004; Su and Bork 2006; Sankey and Bond 2011). First, when the pulse density is low, laser pulses often miss thin plants with vertically oriented leaves or low leaf area indexes, such as sedges, rushes, or grasses. In these instances, only the surface of the Earth is mapped. Likewise, the height of shrub canopies, particularly those with long, linear, highly dissected, or small leaves, such as Salix spp., Tamarix spp., or Artemisia spp., is often underrepresented in LiDAR data because pulses easily penetrate the canopy, producing few first returns from the top. 
Another explanation for poor representation of smaller plants in LiDAR data is that when vegetation is extremely dense, LiDAR pulses may fail to reach the Earth's surface. Under these circumstances, the height of the Earth's surface is overestimated when returns from the low canopy are mistaken for bare earth. Consequently, vegetation height is underestimated when these inflated bare earth points are subtracted from the canopy returns. For instance, in one classification of rangeland vegetation, a LiDAR-derived product classified all shrublands as grasslands, an accuracy of $0.0 \%$ for the category (Bork and Su 2007). This error was attributed to the fact that these shrubs reproduced by root sprouting and formed dense patches. The dense shrub cover resulted in an overestimation of the height of the Earth's surface and an underestimation of canopy height ( $\mathrm{Su}$ and Bork 2006). Although absolute vertical errors tend to increase with vegetation height, these errors have a greater relative effect on the canopy estimates of smaller plants. Because many LiDAR datasets have a vertical accuracy of $\pm 0.15 \mathrm{~m}$, they cannot distinguish between small plants and bare earth.

Given these limitations, low-resolution LiDAR data collected using multiple return systems will be least useful, and high-resolution data collected from waveform ALS or TLS will be most useful, for mapping vegetation during preliminary OHWM delineations. Vegetation indicators found at or below the OHWM, such as the new growth of vegetation in the active channel or a change in vegetation species from herbaceous plants to small shrubs, may be difficult to discern from DSMs or LiDAR-derived products. However, data that were collected shortly after an ordinary event while vegetation is reestablishing in the channel may be useful for estimating the OHWM boundary, provided that plant communities on the floodplain and terrace are well established. Some LiDAR data, such as those collected from TLS, may enable investigators to map differences in height and vegetation density among grasses, herbaceous plants, and shrubs. However, the literature suggests that changes in species composition and stand growth form cannot be determined with accuracy using remote sensing data alone. These types of changes must be confirmed in the field.

In addition to mapping live plant communities, LiDAR data may also be useful for mapping piles of large woody debris. Although drift features are of limited use for determining the OHWM boundary (Mersel et al., in prep.), they can be used as evidence of flow because they verify that a channel is active, particularly in sparsely vegetated arid landscapes. Fu- 
sions of LiDAR data and another type of remote sensing data are most accurate for mapping the distribution of large woody debris. For instance, Eamer and Walker (2010) fused LiDAR data (0.6 to 2.0 points/ $\mathrm{m}^{2}$ pulse density) with $0.20 \mathrm{~m}$ spatial-resolution aerial orthophotography. The result was a $2.0 \mathrm{~m}$ resolution DEM, with $0.20 \mathrm{~m}$ vertical accuracy, that classified Canadian beaches into two land cover classes-sand and large woody debris-with an overall accuracy of $87.3 \%-93.3 \%$ at three locations. However, in heavily vegetated project areas, LiDAR-derived products may be less useful for mapping large woody debris or drift piles. On the vegetated floodplains of the Namoi River in Australia, a LiDAR-derived product was unable to identify locations of large woody debris piles (Frazier et al. 2012). The $1.0 \mathrm{~m}$ resolution DEM produced from an ALS (vertical resolution less than $0.5 \mathrm{~m}$ ) classified with an accuracy of $0 \%$ large woody debris.

\subsection{Mapping topographic patterns and channel morphology}

LiDAR data or products are used in a variety of hydrogeomorphic applications that are potentially useful to regulators, including mapping floodplains and modeling inundation extents (Frazier et al. 2012), modeling floodplain widths (J ones et al. 2007), modeling hydrologics and hydraulics (Hall et al. 2009), determining flow paths (J ones et al. 2008) and connectivity (Lang et al. 2012), delineating ditches (Bailly et al. 2008), and mapping erosion and deposition in coastal dunes (Woolard and Colby 2002). The literature suggests that LiDAR models or products can also be used in preliminary identifications of the OHWM boundary to map channel morphology and changes in topography. DTMs and bare earth DEMs created from the last returns in LiDAR point clouds may be useful for estimating the locations of some of the breaks in slope that signify potential boundaries of the OHWM.

In preliminary delineations of the OHWM boundary, LiDAR data or products can be used to map the approximate location of the OHWM signature across the landscape. Maps created during preliminary delineations provide investigators with a bird's eye view, enabling them to see landscapescale patterns created by the locations of indicators relative to one other. In some landscapes, this type of pattern is difficult to discern at smaller spatial scales, such as at the site level. The literature suggests that LiDAR is commonly used to map riparian systems, including the tops of channel banks, bank slopes, channel beds, bars, benches, and floodplains (Frazier et al. 2012). J ones et al. (2007) mapped up to $88.0 \%$ of channel features, 
including valley floors, terrace fronts, paleochannels, and alluvial fans, using a $2.0 \mathrm{~m}$ resolution LiDAR-derived DEM with a vertical accuracy of $0.10 \mathrm{~m}$. Likewise, a $0.5 \mathrm{~m}$ resolution DEM derived from LiDAR topographic and intensity data classified dry stream channels in southeastern AZ with a UA/PA of 94\%/ 80\% (Farid et al. 2006). On a smaller scale, four riverine habitat categories based on water surface roughness were distinguished using point clouds produced from TLS (Milan et al. 2010). Riffles and pools/ glides were represented with $88 \%-84 \%$ overall accuracy. Cascades/ rapids and runs were more difficult to classify (50\%- 57\% overall accuracy).

In addition to illustrating channel morphology and topographic changes, tools found in LiDAR software and in some GIS enable investigators to use LiDAR data or products to estimate the length and width of hydrogeomorphic features, such as the active channel, the floodplain, or the terrace. These values can then be used to calculate other variables, such as sinuosity. The height or depth of other features, such as the height of a channel bank or the depth of a channel bed, can be directly measured in point-cloud data and DTMs using the tools in LiDAR software. Other variables, such as slope, can be calculated from length and depth measurements. In Figure 5, measurement tools in QTR 7.1.6 are used to measure the depth of a swale $(2.66 \mathrm{~m})$ and to calculate the slope of the bank (0.18) from a DTM derived from a LiDAR point cloud collected using TLS in eastern Vermont.* Channel depth cannot be directly measured when LiDAR data are displayed using a two-dimensional GIS, such as in Figure 6a. However, changes in elevation can be estimated because each pixel contains an elevation value, which is displayed using different colors. It is important to note that most GIS should not be used to directly measure elevation of LiDAR products even though they provide measuring tools and display base map data in three dimensions. In most instances, these measuring tools are calibrated to the base map and not to the imported LiDAR layer.

\footnotetext{
* D. Finnegan and A. LeWinter, unpublished LiDAR data from Ascutney, Vermont. USACE ERDC-CRREL, 2012.
} 
Figure 5. Digital Terrain Model (DTM) derived from LiDAR data collected using a terrestrial platform in eastern Vermont* and displayed using Quick Terrain Reader 7.1.6 (Applied Imagery 2012). In the legend, height is measured in meters. Elevation of the bank and the swale are used to calculate slope $(0.18)$ over a distance of $15 \mathrm{~m}$.

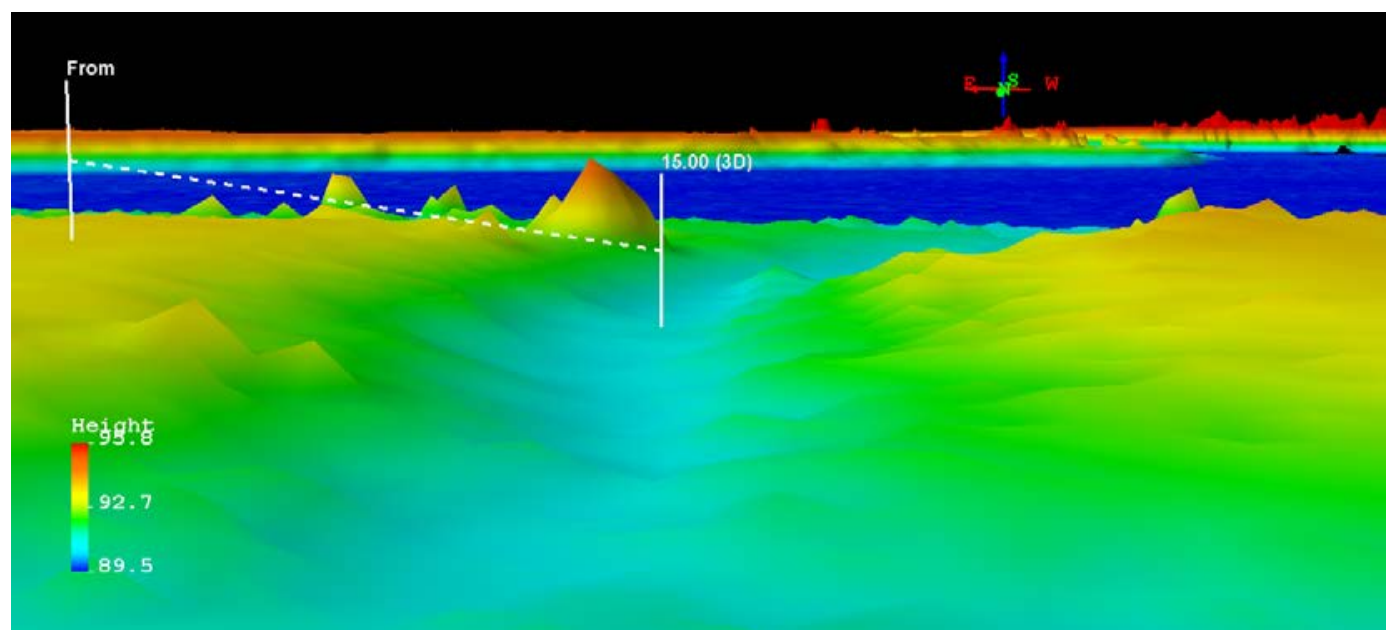

As described in Section 2, the resolution of the data determines which measurements can be made. Features that are shorter than the post spacing in a point cloud or the horizontal resolution of a DEM cannot be accurately discerned or measured. For the purposes of OHWM delineations, small or narrow features, such as some point bars or coarse woody debris, will not be accurately represented in LiDAR data. For the same reason, sharp breaks in slopes, such as those associated with some channel banks, ditches, or canals, are not well represented in LiDAR data. In addition, LiDAR data may not represent flow direction accurately because highresolution data may show numerous small changes in elevation over a relatively small area. These small-scale discrepancies in topography may need to be smoothed before flow direction can be accurately determined. In these instances, data that have been enhanced with breaklines will be most useful for delineation purposes.

For preliminary OHWM delineations, measurements made using LiDAR data should be considered estimates. All GIS measurements should be verified in the field (Hall et al. 2009; Perroy et al. 2010). It is extremely important to examine metadata and to ground truth, particularly when using LiDAR data that were originally collected for a purpose other than OHWM delineations. As described in Section 2, the data collection and processing methods and purpose for which the data were collected can have a great impact on the product. Hall et al. (2009) illustrate why inves-

* D. Finnegan and A. LeWinter, unpublished LiDAR data from Ascutney, Vermont. USACE ERDC-CRREL, 2012. 
tigators cannot rely on remotely sensed data alone. They used a combination of hyperspectral imagery and a $1.0 \mathrm{~m}$ resolution LiDAR-derived DEM with a $0.15 \mathrm{~m}$ vertical accuracy to map a reach of the South Fork of the Humboldt River in Nevada. The DEM represented the last returns of a LiDAR point cloud originally collected for fire management purposes by the Department of the Interior's Bureau of Land Management (BLM). It was used to measure stream channel cross sections, to develop a longitudinal profile of a reach, and to measure sinuosity and channel slope. These measurements and Manning's equation were also used to calculate discharge for the reach. Gage data were used to check the accuracy of the results. Unexpectedly, the flow rate calculated from the LiDAR-derived product was 1.82 times slower than that of the gage data from the same time period. Although gage data are not error free (Curtis et al. 2011), Hall et al. (2009) determined that, on average, the DEM underestimated the height of the water surface by $15.25 \mathrm{~cm}$. The error was attributed to the infrared LiDAR processing algorithms, which were designed to calculate elevation in terrestrial systems. Terrestrial algorithms distort the bathymetric portion of the returns because they assume that LiDAR pulses are traveling at a constant rate through one medium - air. However, in riverine systems, pulses actually travel through both water and air at two different rates (Kinzel et al. 2007). This is one reason that the location of OWHM indicators and all estimates made using LiDAR data must be verified in the field. Other sources of error in LiDAR topographic data are discussed in Section 4.2.

\subsection{Mapping changes in sediment texture}

The literature suggests that most LiDAR models or products are unable to represent small changes in sediment texture, the third indicator involved in preliminary identifications of the OHWM boundary. Although LiDAR technology has been used in conjunction with field data to document correlations among elevation, duration of ponding, and fine-scale changes in sediments (Lichvar et al. 2008), the sediment changes were not measured using LiDAR data. The fine-scale changes in sediments, such as mud crack width and depth, were measured in the field. Given the current technology, LiDAR products are useful for mapping large changes in sediment texture only, such as a change from boulders to gravel or boulders to sand. A 1.0 m resolution LiDAR-derived DEM with a vertical resolution of less than $0.5 \mathrm{~m}$ cannot detect differences among smaller substrate classes, such as cobble, gravel, sand, and mud (Frazier et al. 2012). 
However, as technology advances and more datasets become available, point clouds, DTMs, and LiDAR-derived DEMs may become more useful for mapping changes in sediment texture associated with the OHWM boundary. The literature suggests that high-resolution LiDAR data collected using TLS can map most changes in sediment texture associated with placement of the OHWM boundary. One example, a TLS dataset of 3.8 million points, which had a mean spacing of $0.012 \mathrm{~m}$ and a vertical accuracy of $0.009 \mathrm{~m}$, documented differences in grain roughness from $40 \mathrm{~mm}$ ( $\left.\mathrm{D}_{16}\right)$ to $130 \mathrm{~mm}\left(\mathrm{D}_{84}\right)$ in a gravel bar (Heritage and Milan 2009). Likewise, Hodge et al. (2009b) examined differences in sediment sizes in the gravel bars of two channels by using a TLS with a $4 \mathrm{~mm}$ diameter laser footprint and a minimum point spacing of $1.2 \mathrm{~mm}$ to create a $1.0 \mathrm{~mm}$ resolution $\mathrm{DEM}$. The average sediment size $\left(\mathrm{D}_{50}\right)$ ranged from 32 to $63 \mathrm{~mm}$ in the first channel and from 18 to $33 \mathrm{~mm}$ at the second site. Data collected at this scale could be used in preliminary delineations to estimate the location of the OHWM boundary and to document changes from sand to cobbles to boulders. However, it would be unable to distinguish between sand and silt.

\subsection{Conclusions}

In summary, the literature suggests that LiDAR data and products can be useful for preliminary delineations of the OHWM boundary. Before the channel signature is interpreted, the recent flow history of the site should be determined, if possible. In some cases, recent large floods will have altered the OHWM signature, and LiDAR data will not reflect "ordinary" conditions at the site. If "ordinary" conditions exist, two OHWM indicators-vegetation density changes and break in slope-may be interpreted through LiDAR data. Currently, only large sediment texture changes can be detected. Vegetation density changes are best observed in landscapes dominated by trees and tall shrubs. Because LiDAR consistently underestimates vegetation height, it will be less useful for estimating changes in vegetation density in sparsely vegetated areas and in areas dominated by short shrubs, herbs, and grasses. However, ephemeral and intermittent channels are often present in these sparsely vegetated regions. LiDAR is capable of capturing many of the topographic changes in channel morphology in these dry systems. The horizontal resolution and vertical accuracy of the data determine if the OHWM break in slope can be measured with sufficient accuracy. Particular attention must be paid to determining if the depth of the channel is less than the vertical accuracy of the LiDAR data. Although LiDAR provides an opportunity to view the OHWM signa- 
ture at the landscape scale, all information gathered from LiDAR-derived products during preliminary delineations of the OHWM boundary must be verified in the field. 


\section{Using LiDAR Data in the Preliminary Data- Gathering Stage of Wetland Delineations}

As LiDAR technology advances, data collection increases, and LiDAR data are used more frequently in a variety of wetland applications. For instance, in 2010, the Minnesota Department of Natural Resources began a statewide National Wetland Inventory mapping project using LiDAR and radar imagery and $0.6 \mathrm{~m}$ digital ortho and stereo imagery (Tande and Michaelson 2011). USACE's Wilmington District and Raleigh Field Office have used LiDAR data for preliminary delineations (Lekson 2012). Having provided evidence of spoil piles, fill, and other anthropogenic disturbances, LiDAR data are potentially useful for enforcement (Shaeffer 2008). This section also provides many examples in which LiDAR data or products have been used for wetland identification and mapping. However, it is important to note that the studies cited here were based on many different definitions of wetlands. With the exception of Shaeffer (2008), Lichvar et al. (2006), and Russell et al. (2010), the research described here did not explicitly use hydrophytic vegetation, hydric soils, and wetland hydrology as the criteria to determine wetland presence or absence. For example, Lang and McCarty (2009) used LiDAR to map inundated areas; detailed examination of soils and vegetation was not mentioned. Maxa and Bolstad (2009) ground-truthed LiDAR-derived wetland maps primarily by vegetation type. The hydrologic criteria used to distinguish wetlands from uplands were not stated. J enkins and Frazier (2010) delineated "upland swamps" (headwater wetlands surrounded by upland forest) remotely using LiDAR and multispectral imagery. They assessed accuracy by using image-interpretation-based point counting rather than ground truthing. Therefore, the end products of wetland research, such as classification accuracies, should be viewed critically when applied to delineation procedures as accuracies are likely to change with the definition of "wetland."

The literature suggests that LiDAR data and products will be most useful in the preliminary data gathering stage of wetland determinations. During this off-site stage of the investigation, the USACE Wetland Delineation Manual recommends examining many types of remote sensing data, including (but not limited to) NWI products, Natural Resources Conservation Service (NRCS) soil surveys, USGS quadrangle maps (1:24,000), USGS land use and land cover maps, and aerial/ satellite imagery (Envi- 
ronmental Laboratory 1987). LiDAR data and products can be used in conjunction with other remote sensing data to plan an on-site investigation by dividing a project area into land cover types (LCTs) and, in some instances, drawing preliminary wetland boundaries that can be refined during the on-site investigation. However, LiDAR data do not contain enough information to make wetland determinations for regulatory purposes.

Before LiDAR data are used in a preliminary investigation, the temporal context of the data should be examined. First, the date of the LiDAR survey shown in the metadata should be compared with the current date. If there has been a large disturbance event between the two dates, the data should be used with caution. For instance, LiDAR data collected prior to a hurricane or tropical storm may be less useful because storm events can cause extreme erosion, deposition, and damage to vegetation (Enwright et al. 2011). Other natural disturbances, such as wildfires, avalanches, mudslides, or beaver activity, may increase or decrease wetland area (Environmental Laboratory 1987), making older LiDAR datasets obsolete. Conversely, data collected prior to an unpermitted anthropogenic disturbance, such as unauthorized fill, could be used along with other remote sensing resources to approximate the location of the pre-disturbance wetland boundary. A second temporal consideration is whether the data were collected during the growing season as the definition of wetland hydrology is linked to the concept of growing season. Investigators should compare the LiDAR collection date to the dates of the growing season, listed in an NRCS WETS Table (http://www.wcc.nrcs.usda.gov/climate/wetlands.html). Growing season is discussed in greater detail in Section 4.3.

Provided that temporal relationships between data collection date, disturbance events, and growing season are recognized, LiDAR point clouds, models, or products may help investigators discern vegetation patterns, changes in topography, and inundation patterns. However, LiDAR data should not be used to make vegetation determinations, to map hydric soils, or to determine whether wetland hydrology is present. All areas identified as having the potential to support hydrophytic vegetation, hydric soils, or wetland hydrology should be verified during the on-site field investigation. 


\subsection{Mapping vegetation patterns}

The literature suggests that, in some instances, LiDAR data or products may help investigators discern vegetation patterns during the off-site, data-gathering portion of a wetland delineation. During this preliminary investigation, investigators summarize all remote sensing information available and identify LCTs that require less field sampling to verify, such as obvious nonwetlands and the interiors of obvious wetlands. During the on-site portion of the investigation, sampling is focused on transition zones between obvious wetlands and obvious nonwetlands. A project area may be divided into LCTs based in part on vegetation patterns discerned from LiDAR data or products. Figure 6 provides an example of several types of remotely sensed data from Davis Park, New York, including highresolution satellite imagery, NWI wetland maps, National Land Cover Data (NLCD), and a hydric soil map. Three LiDAR products, a DEM, contour lines, and a CHM, are also shown. These data were used to divide a hypothetical project area into three LCTs based on plant height and growth form. The LiDAR CHM shows three height classes of vegetation (Figure 6b): short (blue: $\sim 0-3 \mathrm{~m}$ ), intermediate (yellow: $\sim 4-6 \mathrm{~m}$ ), and tall (green: -6- $10 \mathrm{~m}$ ). USGS land cover maps (Figure 6c) and NWI wetland polygons (Figure 6a) suggest that the vegetation in LCT1 is primarily herbaceous; the vegetation in LCT2 is composed of shrubs and herbs; and LCT3 is composed of shrubs, barren land, and a hiking trail. Overall, the LiDAR CHM, the NWI wetland polygons, and the hydric soil map suggest that less sampling effort is needed in LCT1, which is dominated by 0 to 3 $\mathrm{m}$ herbaceous vegetation, and LCT3, which is characterized by 6 to $10 \mathrm{~m}$ shrubs and barren land, because they appear to be obvious wetland and upland, respectively. These remotely sensed resources suggest that after LCT1 and LCT3 are verified in the field, the boundary investigation should focus on LCT2. 
Figure 6. Comparison of three LiDAR products and four other types of remotely sensed data for a hypothetical wetland delineation near Davis Park on Fire Island, New York.

a. 1.0 m LiDAR-derived digital elevation model and contour lines (Nayegandhi et al. 2010), overlain by US Fish and Wildlife Service's (FWS) National Wetland Inventory (NWI) wetland polygons (USFWS 2012) mapped at a scale of 1:24,000 and displayed using ArcMap 10.1.

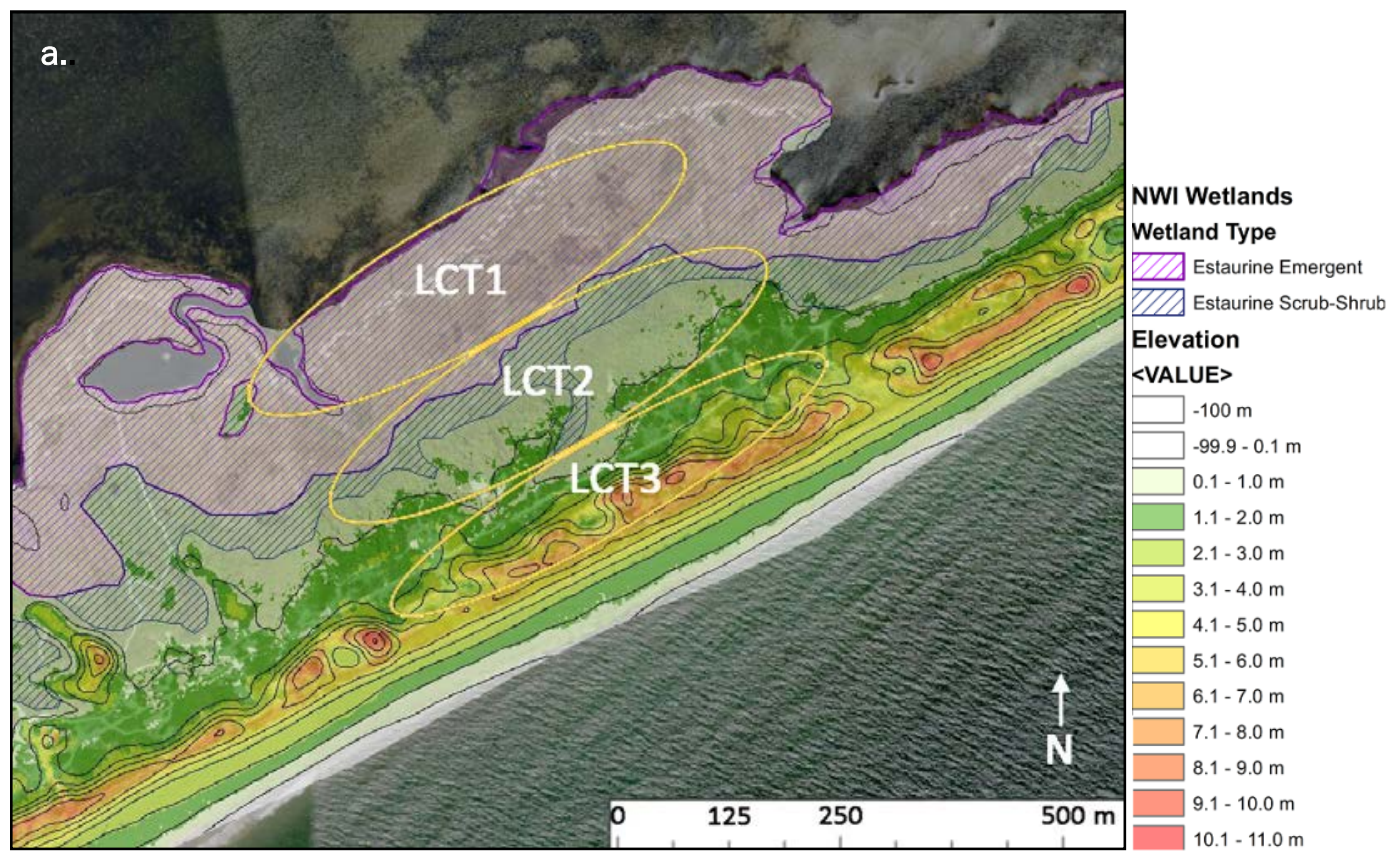

b. 1.0 m LiDAR-derived CHM (Nayegandhi et al. 2010) displayed using Google Earth Pro (Terra Metrics 2010).

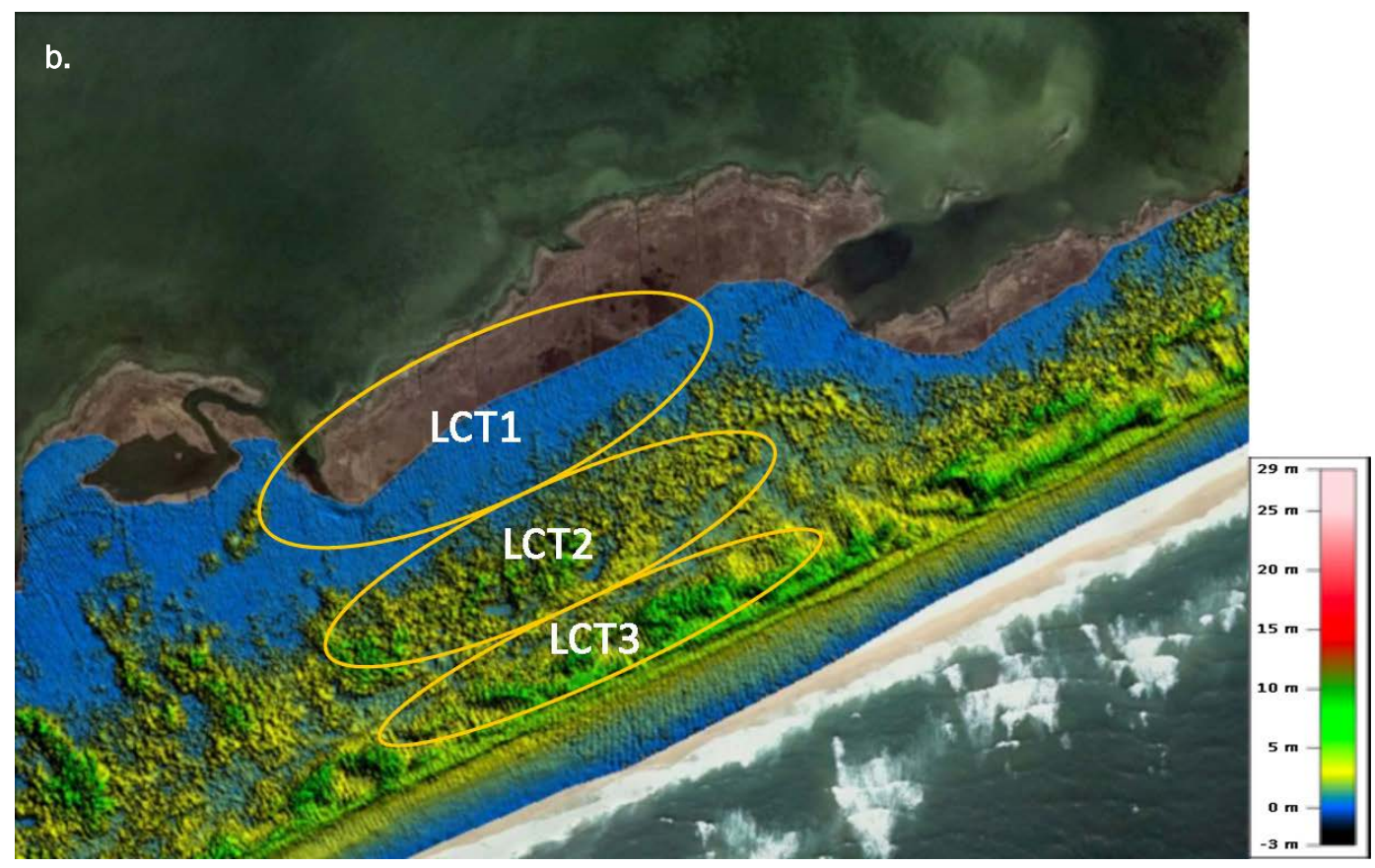


Figure 6 (cont.). Comparison of three LiDAR products and four other types of remotely sensed data for a hypothetical wetland delineation near Davis Park on Fire Island, New York.

c. NLCD mapped at a $30 \mathrm{~m}$ resolution (Vogelmann et al. 2001) displayed using Global Mapper 13.0.

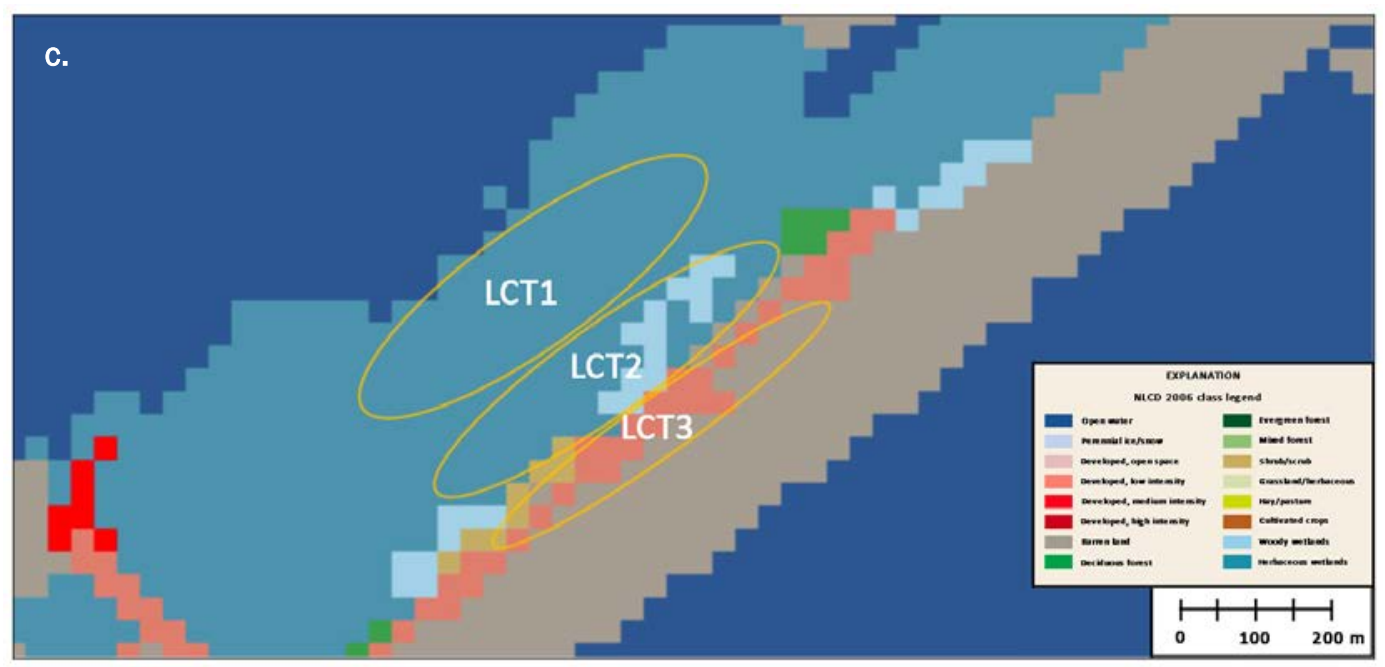

d. High-resolution satellite imagery overlain by NRCS's Soil Survey Geographic soil order polygons (NRCS 1994) mapped at a scale of 1:577,000 to 1:1,840,000 and displayed using CorpsMap 2.7.

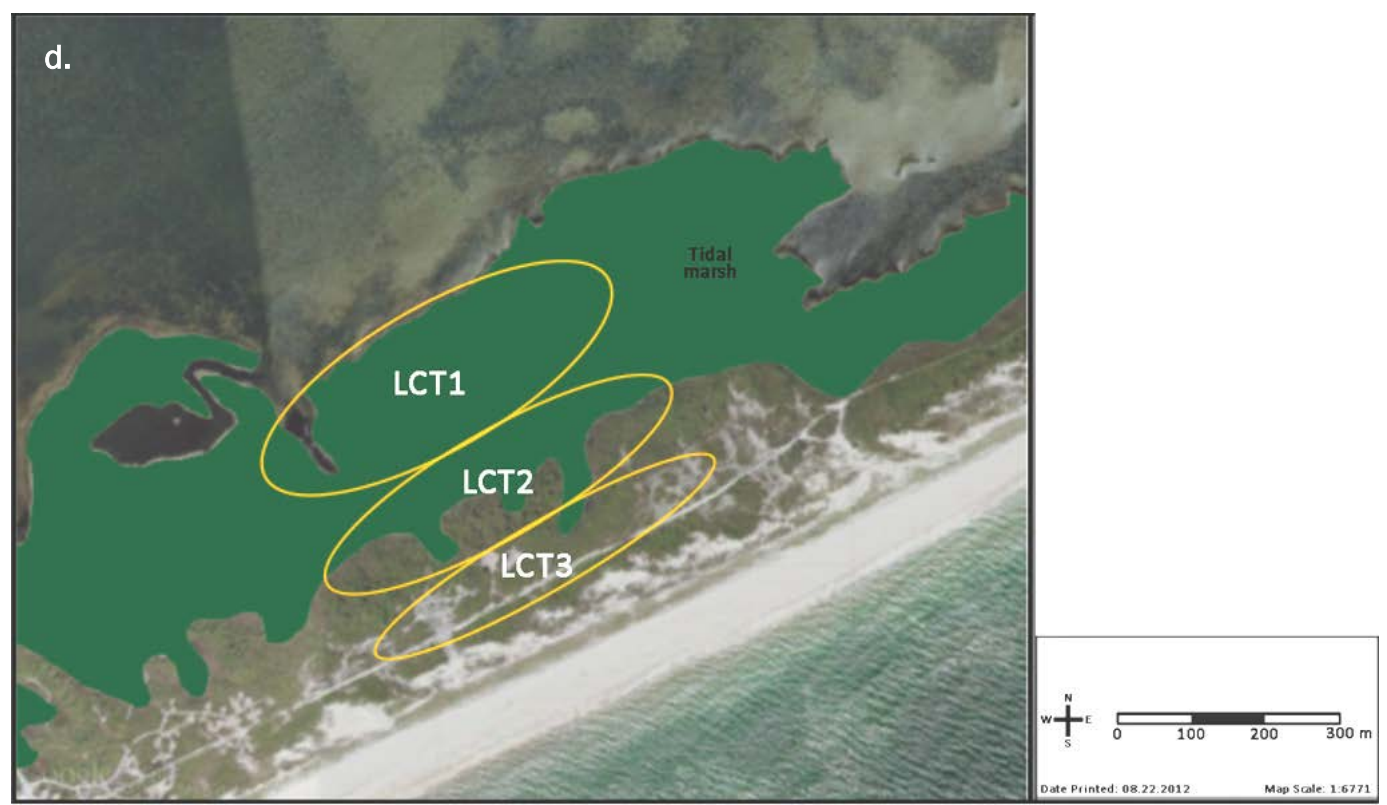

In the preliminary data-gathering stage of a delineation, the literature suggests that LiDAR data or products will be most useful for mapping wetland boundaries characterized by abrupt transitions from wetland to upland that coincide with a significant change in vegetation height (e.g., a scrub-shrub wetland located in the midst of a forested landscape). Under these circumstances, a combination of a 1.0 m LiDAR-derived CHM, $2.4 \mathrm{~m}$ 
resolution multispectral imagery, and $0.20 \mathrm{~m}$ orthorectified aerial photography delineated shrub-sedge-dominated wetlands from adjacent upland forest with a UA/ PA of 97\%/96\% (J enkins and Frazier 2010). LiDAR products will also be useful for delineating sparsely vegetated wetlands from densely vegetated uplands, or the reverse. For instance, in northcentral California, sparsely vegetated vernal pools, characterized by long periods of inundation, were easily identified and mapped using a $2.0 \mathrm{~m}$ resolution LiDAR-derived DEM with $5.0 \mathrm{~cm}$ vertical accuracy created from a fusion of LiDAR data and IKONOS satellite imagery (Lichvar et al. 2006). In this study, wetland mapping using remote sensing identified $169 \%$ more vernal pools and swales than field mapping alone. However, when vegetation height and density are similar on both sides of the wetland boundary, LiDAR data and products will be less useful.

Although LiDAR data or products may be used to map LCTs based on vegetation, they should not be used to make hydrophytic vegetation determinations for two reasons. First, LiDAR cannot identify plants at the species level. The literature provides evidence that LiDAR data alone cannot distinguish among species in the same land cover class (e.g., trees) although accuracy improves somewhat when LiDAR is used in combination with multispectral imagery. For instance, in Wisconsin forests, evergreen conifers were classified with UA/PAs of $80.3 \% / 86.4 \%$ using IKONOS satellite imagery fused with a $1.0 \mathrm{~m}$ resolution LiDAR-derived DEM with a vertical accuracy of $0.15 \mathrm{~m}$ (Maxa and Bolstad 2009). However, individual species, such as Larix laricina (American larch), Picea mariana (black spruce), and Thuja occidentalis (eastern arborvitae), often could not be distinguished from one another. Very few of the pixels representing L. laricina were classified correctly $(\mathrm{PA}=14.3 \%)$, and the likelihood of a pixel representing actual field conditions was low (UA $=50.0 \%$ ). Likewise, in a Connecticut River tidal marsh, a $2.4 \mathrm{~m}$ resolution LiDARderived DEM (vertical accuracy of $0.06 \mathrm{~m}$ ) used in combination with multispectral signatures of three dominant graminoids had difficulty distinguishing Typha spp. (cattail) from Phragmites australis (common reed) and Spartina patens (salt-meadow cord grass) (Gilmore et al. 2008). Although most of the Typha spp. plots were classified correctly (PA = $95 \%$ ), the likelihood of a pixel representing actual field conditions was very low $(\mathrm{UA}=36 \%$ ). The other two species were classified fairly well, particularly when they occurred as monocultures. P. australis had UA/ PA accuracies of $96 \% / 66 \%$, and S. patens had UA/PA accuracies of 67\%/69\%. 
A second reason why LiDAR data should not be used to make hydrophytic vegetation determinations is that the data often cannot determine if vegetation is present. As described in Section 3.1, LiDAR data consistently underestimate vegetation height. Therefore, vegetation units dominated by trees and tall shrubs are usually classified most accurately. Differences among classes of shorter vegetation, such as small shrubs, grasses, terrestrial or aquatic herbs, and bare earth, often cannot be distinguished. In Figure $6 \mathrm{~b}$, the CHM shows that about half of LCT1 is vegetated. The remainder is mapped as bare earth. The NWI polygons (Fig. 6a) and the NLCD (Fig. 6c) show that LCT1 is completely covered by emergent herbaceous vegetation, extending farther north and covering twice as much area as the LiDAR-derived CHM suggests.

Overall the literature suggests that, in some wetland types, LiDAR data could be used to separate a project area into LCTs based on differences in vegetation height. However, field validation of these LCTs is necessary. Because LiDAR data cannot identify plants to the species level and sometimes cannot even determine if vegetation is present, vegetation determinations should never be made based solely on point-cloud data or on LiDAR-derived products.

\subsection{Mapping topographic and soil patterns}

As described in Section 2.1, infrared LiDAR uses the last return signals from lower-energy, longer-wavelength, near-infrared pulses (1064 or 1550 $\mathrm{nm}$ ) to determine the height of the Earth's surface. The resulting topographic data can be used to model the Earth's surface across a project site during the data-gathering stage of wetland delineations. Provided that there have been no severe disturbance events since the data collection date, LiDAR topographic data can be used to identify low areas with the potential to accumulate water. Because these data provide no evidence of the presence or absence of surface water, they should not be used as evidence of wetland hydrology. However, topographic data will be useful for dividing a project area into LCTs and for focusing a field investigation on areas with the potential to support wetland hydrology. During the preliminary data-gathering stage of wetland delineations, point-cloud data, models, LiDAR-derived products, and secondary products may be useful to regulators.

Point clouds and DTMs can be used to identify topographic lows in a landscape, to estimate the height of a topographic break, or to calculate the 
slope of an LCT. Length, width, and height can be directly measured using tools in LiDAR software and in some GIS although, as described previously, narrow or small features that are shorter than the point spacing or smaller than the vertical accuracy of the data cannot be accurately measured. For delineation purposes, changes in elevation over a specific distance can be measured in each LCT. Slopes can be estimated from these measurements and used in support of a secondary hydrology indicator, geomorphic position. During the data-gathering stage of wetland delineations, measurements made using LiDAR data should be considered estimates. All measurements should be verified in the field (Hall et al. 2009; Perroy et al. 2010).

LiDAR-derived products, such as DEMs and contour lines, may also be used to identify low areas in the landscape with the potential to pond water. Although elevation cannot be directly measured in two-dimensional LiDAR-derived DEMs, each pixel contains an elevation value that is displayed in raster format using different colors. For example, the LiDARderived DEM in Figure 6a shows that most of LCT3 ranges from $1.1 \mathrm{~m}$ (green shading) to $11.0 \mathrm{~m}$ (red shading) in elevation. As always, spatial resolution must be taken into account because both horizontal resolutions and vertical accuracy limit the conclusions that can be drawn from a dataset. Topographic features that are shorter in length or height than the horizontal resolution or vertical accuracy of a dataset cannot be accurately measured. For instance, a 1.0 m LiDAR-derived DEM with a vertical resolution of $0.15 \mathrm{~m}$ could not be used to discern sedge tussocks $0.75 \mathrm{~m}$ wide and $0.18 \mathrm{~m}$ tall.

Contour lines derived from a LiDAR point cloud display elevation data in two-dimensional vector format (Fig. 6a). In the context of wetland delineation, the widely spaced LiDAR-derived contour lines in Figure 6a show that the elevation of LCT1 is close to sea level ( 0 to about $1.0 \mathrm{~m}$ above sea level) and relatively flat, suggesting that it is more likely to pond water than LCT3 in which the contour lines are more closely spaced and the elevation ranges from 1.1 to $11.0 \mathrm{~m}$ above sea level. As with the vegetation data, the topographic data suggest that field sampling should focus on the southern edge of LCT2 where the elevation gradually increases from 0.1 to $2.0 \mathrm{~m}$. The NWI wetland polygons (Fig. 6a), NLCD (Fig. 6c), and NRCS (Fig. 6d) hydric soil maps show similar patterns, suggesting that wetland hydrology and hydric soils are mostly absent in LCT3 but are present in all of LCT1 and in the northern portion of LCT2. 
Secondary products displayed in two-dimensional raster format may also be useful to investigators, when available. LiDAR-derived products, such as bare-earth DEMs, and mathematical formulas are used to create secondary products that predict variables that were not directly measured, such as slope, aspect, and curvature (Shaeffer 2008) or terrain shape and lagg width (Richardson et al. 2010). In predominantly flat (455- $500 \mathrm{~m}$ above sea level) Wisconsin forests, terrain shape and slope products, calculated from a $1.0 \mathrm{~m}$ resolution LiDAR-derived DEM (vertical accuracy of $0.15 \mathrm{~m}$ ), have been used to map wetlands (Maxa and Bolstad 2009). The DEM was used to calculate the terrain shape and slope of features in the study area. Negative values for terrain shape indicated topographic depressions while positive values suggested convex landforms. These secondary products and IKONOS satellite imagery distinguished uplands from wetlands fairly well. Pixels representing uplands were usually classified correctly ( $\mathrm{PA}=89.8 \%$ ) although the likelihood of the pixel representing upland conditions in the field was lower (UA $=82.2 \%$ ).

However, the literature suggests that there is some error associated with LiDAR topographic data. The error tends to be greatest in areas characterized by steep slopes and dense vegetation. Error associated with steeply sloping terrain occurs in two ways (Deems et al. 2013). As mentioned previously, vertical accuracy depends on horizontal accuracy. Horizontal errors, which tend to increase with flight altitude, result in a point being incorrectly located on a planimetric surface. The incorrect horizontal location points can cause vertical errors, particularly in uneven landscapes. Vertical error may also be caused when LiDAR laser footprints spread on a sloped surface, increasing the signal-to-return time and inflating the recorded distance from the scanner.

As described in Section 3.1, elevation may also be overestimated when dense vegetation prevents LiDAR pulses from striking the Earth; processing algorithms may interpret the last return as representing bare earth when it actually represents low vegetation (Hopkinson et al. 2004). For this reason, errors in topographic data tend to be greatest in landscapes characterized by several vegetative strata (Clark et al. 2004). For instance, densely vegetated swamps dominated by deciduous trees, conifers, and Alnus incana (=Alnus rugosa) (speckled alder) could not be distinguished from surrounding upland forest by using topographic LiDAR data alone (Hogg and Holland 2008). Likewise, a landscape-level study of aspen parkland found that LiDAR data overestimated the elevation of steeply 
sloping forest stands and underestimated the elevation of grasslands and wet meadows (Su and Bork 2006). Interestingly, other work suggests that the reverse is true at smaller scales. When compared to field measurements along $120 \mathrm{~m}$ peatland transects, LiDAR topographic data overestimated lower-elevation features and underestimated higher-elevation features, muting the overall topographic heterogeneity (Richardson et al. 2010). Overestimates of lower-elevation features, such as hollows, were attributed to the presence of dense vegetation and the GPS unit compressing the peatland surface during ground truthing. Most importantly, the literature suggests that classification and mapping errors tend to be greatest in areas characterized by a gradual transition from upland to wetland (Hogg and Holland 2008). Therefore, topographic patterns discerned using LiDAR data should be verified in the field. Field validation of LiDAR topographic data is essential before using them as evidence of a secondary hydrology indicator, such as geomorphic position, microtopographic relief, raised ant mounds, or frost-heave hummocks, particularly in densely vegetated or conifer-dominated wetlands or steeply sloped wetlands, such as some fens.

Although LiDAR data cannot be used to map changes in soil saturation (Garroway et al. 2011), soil wetness indices, another secondary product created from LiDAR-derived DEMs, may be useful to investigators. Soil wetness indices (Moore et al. 1993; Murphy et al. 2007), which are also referred to as topographic wetness indices (Böhner et al. 2002; Shaeffer 2008; Shoutis et al. 2010), use topographic data from LiDAR-derived DEMs and a mathematical formula to predict areas where soils are likely to be saturated or inundated given their topographic position in the landscape. Wetness indices are often calculated using the general formula

$$
W I=\ln (A / \tan \beta)
$$

where $A$ is the catchment area $\left(\mathrm{m}^{2} / \mathrm{m}\right)$ that drains to the point and $\beta$ is the slope in degrees (Moore et al. 1993). This formula produces large index values in pixels that are likely to contain wet soils or wetlands and low index values in pixels that are likely to contain drier soils or nonwetlands located farther from water sources. Before an index can be used for delineation purposes, the formula used to calculate the index should be examined because other WI formulas, such as $\mathrm{WI}=\ln (\mathrm{A} / \beta)$, produce low values for wet soils and high values for drier, nonwetland soils (Murphy et al. 2007). In addition, the source and spatial resolution of the topographic 
data should be examined because wetness indices are constructed from DEMs produced from other types of remotely sensed data collected at different spatial resolutions. For instance, Murphy et al. (2007) developed a $10 \mathrm{~m}$ resolution soil wetness index from photogrammetrically derived topographic data from 1:35,000 digital aerial photographs.

The literature provides conflicting evidence regarding the utility of secondary products derived from LiDAR topographic data. In predominantly flat, deciduous forests of Maryland, a wetness index, constructed from a LiDAR-derived DEM with a vertical accuracy of less than or equal to 0.15 $\mathrm{m}$, was less able to distinguish inundated areas from non-inundated areas when compared to LiDAR intensity data (Lang and McCarty 2009). However, other research suggests that the secondary products derived from a $6 \mathrm{~m}$ resolution LiDAR-derived DEM are able to predict the presence of jurisdictional wetlands. Shaeffer (2008) modeled the presence and absence of jurisdictional wetlands in 18 study sites throughout Beaufort County, NC, by using a topographic wetness index and localized LiDAR elevation data. Ground truthing suggested that the model underestimated the presence of jurisdictional wetlands at a landscape scale (the overall classification accuracy was 79.8\%). At a site-level scale, LiDAR topographic data and two secondary products-curvature and slope-predicted the presence of jurisdictional wetlands with an overall classification accuracy of 93.3\%. However, the presence of jurisdictional wetlands was overestimated at this fine scale. Russell et al. (2010) reached similar conclusions. They predicted the presence of jurisdictional wetlands using LiDAR topographic data and five secondary products. In three study areas, classification accuracy ranged from $58 \%$ to $71 \%$. The model tended to miss small wetlands and overestimate the area of larger wetlands.

\subsection{Mapping hydrologic patterns}

The literature suggests that LiDAR intensity data and bathymetric LiDAR data can be used to map hydrologic patterns in a project area during the data-gathering stage of wetland delineations. LiDAR intensity data, which measure the strength of the last return pulse, are often used to model the presence or absence of surface water. Green or bathymetric LiDAR use high-energy, short-wavelength LiDAR pulses (520 nm) to measure water depth and to map benthic habitats. Both types of data may provide evidence of wetland hydrology, provided that their temporal limitations are recognized. Investigators should examine metadata to determine the collection date because the wetland hydrology criterion has two temporal 
components that must be met. First, water must be within the top 12 in. $(30 \mathrm{~cm})$ of the soil surface for 14 or more consecutive days. Second, the 14 consecutive days must occur during the growing season (USACE 2005). Like all remotely sensed data, LiDAR data represent a snapshot in time. Point clouds and LiDAR-derived products cannot satisfy the first requirement of showing water ponded or at the soil surface for 14 or more consecutive days because they represent a single collection date and provide no information about the frequency or duration of inundation. However, it may still be possible to determine that a project area is inundated or saturated at different times during the growing season if LiDAR intensity data are used in conjunction with other remotely sensed data, such as visible inundation (primary hydrology indicator) or saturation (secondary hydrology indicator) on satellite imagery or aerial photography collected at a different time in the growing season.

Intensity data must be collected during the growing season if they are to be used as evidence of wetland hydrology. To determine if data were collected during the growing season, the collection date shown in the metadata should be compared to the dates of the growing season shown in a WETS table (http://www.wcc.nrcs.usda.gov/climate/wetlands.html). LiDAR data could be used as evidence of wetland hydrology most easily in the southern United States where the growing season can be year round in some counties. However, data collected during rainy seasons or in a year of above-average rainfall could overestimate wetland acreage while data collected during dry seasons could underestimate wetland acreage (Henry and Gonzalez 2005). Some federal agencies, such as the USGS, recommend collection of LiDAR data during leaf-off when there is no snow cover and no flooding or unusual inundation (USGS 2010) although collection dates ultimately depend on the research question. The literature does suggest that LiDAR data are most accurate when collected during leaf-off (Hogg and Holland 2008; Lang and MoCarty 2009) because vegetation is the greatest source of topographic error in LiDAR-derived DEMs (Su and Bork 2006). In the north, leaf-off and growing season guidelines effectively restrict data collection to late fall and early spring. LiDAR intensity data collected at these times should be used with caution, however, because the extent of inundation during leaf-off may not be representative of conditions during the growing season. It is not unusual for water to pond temporarily during leaf-off in nonwetlands for several reasons: spring snowmelt or fall rains generate surface flow, evapotranspiration rates are reduced during leaf- 
off, and partially frozen soils can reduce infiltration rates. LiDAR intensity data collected under these conditions could overestimate wetland area.

As mentioned in Section 2, LiDAR intensity data represent differences in the strength of the return signals across a landscape. In general, clear, standing water absorbs or scatters $1064 \mathrm{~nm}$ wavelength, near-infrared LiDAR pulses, producing very weak returns. In terrestrial landscapes, water bodies and wetlands characterized by standing water can be classified based on this signature. The literature provides conflicting reports regarding the classification accuracy of intensity data. In a Maryland watershed, inundated areas were mapped using intensity data derived from a LiDAR point cloud with a $0.15 \mathrm{~m}$ vertical accuracy and about a $0.40 \mathrm{~m}$ post spacing collected early in the growing season (27 March) (Lang and McCarty 2009). With an overall accuracy of $96.3 \%$, intensity values from 0 to 50 were used to distinguish inundated from non-inundated forest. Likewise, in an estuarine ecosystem near Nova Scotia, LiDAR data collected at the beginning of the growing season (20-25 April), before leaf-out, were used to construct a 1.0 m resolution LiDAR-derived DEM with a $0.03 \mathrm{~m}$ vertical accuracy (Brennan and Webster 2006). Intensity data with values of less than 0.25 classified the intertidal zone and open water with UA/ PAs of $98.3 \% / 99.8 \%$, and $100 \% / 100.0 \%$, respectively.

In northern coastal Spain, Chust et al. (2008) compared the classification accuracy of LiDAR-derived intensity data with topographic data when both were combined with multispectral satellite imagery. A $1.0 \mathrm{~m}$ resolution, bare-earth DEM produced from LiDAR topographic data (collected from J anuary to May 2005, vertical accuracy of $0.15 \mathrm{~m}$ ), combined with multispectral satellite imagery, classified and mapped wetlands with UA/ PAs of $99.0 \% / 77.5 \%$. A combination of multispectral imagery and LiDAR intensity data was slightly less accurate. Most of the plots representing inundated areas were classified correctly $(\mathrm{PA}=68.8 \%)$, and the likelihood of these pixels representing actual field conditions was high (UA $=91.1 \%)$.

However, there is also evidence that intensity data collected using $1064 \mathrm{~nm}$ wavelength pulses are unreliable under some environmental conditions. Another Nova Scotia study, which used intensity data collected at the beginning and end of the growing season (31 March and 30 September), showed no correlation between the intensity of LiDAR returns and the presence of soil surface water (Garroway et al. 2011). These results 
suggest that, under some conditions, intensity data may be unreliable for wetland mapping. First, some nonwetland ecosystems may generate lowintensity returns, suggesting the presence of surface water when in fact there is none. Low-intensity returns have been reported from the Earth's surface under conifer canopies (Lang and McCarty 2009) and from row crops in agricultural fields (Garroway et al. 2011). Intensity data are most useful when collected in sparsely vegetated areas or during leaf-off because vegetation has a greater effect on return signal intensity than ponded water. An instance in which intensity data may be unreliable is when the water's surface is rough/ rippled, turbid, polluted, or covered with organic debris, such as leaves (Milan et al. 2010; Newcomb and Lang 2012). Under these conditions, water bodies may generate strong returns similar to those produced in terrestrial systems. Intensity data also cannot distinguish seasonally inundated wetlands, such as Delmarva bays, vernal pools, or prairie potholes, from surrounding uplands if they were not inundated at the time of data collection (Lang and McCarty 2009). Likewise, intensity data will be unable to distinguish seasonally saturated wetlands, such as wet flat woods, from surrounding upland unless the data were collected in an unusually wet year.

There are also a few technical concerns associated with the use of LiDAR intensity data. Raw intensity data should not be used for regulatory purposes because they contain a great deal of noise, which reduces their ability to distinguish inundated from non-inundated areas. Lee filtering reduces the range of the data and improves the separation between the inundated and non-inundated classes (Chust et al. 2008; Lang and McCarty 2009). A final concern is that intensity values vary with the type of scanner used. Accurate inundation maps have been produced from data having intensity values of different orders of magnitude, less than 0.25 (Brennan and Webster 2006) and 0-50 (Lang and MoCarty 2009). Therefore, no universal standard or specification for LiDAR intensity can be set for regulatory purposes. For these reasons, project areas mapped as inundated or non-inundated based on LiDAR intensity data must always be ground truthed during a field investigation.

Topographic data collected by green LiDAR pulses may also be used to model inundation. Unlike intensity data, which represent the energy of the last return, LiDAR topographic data model the height of the Earth's surface. Green or bathymetric LiDAR uses high-energy, short-wavelength LiDAR pulses (520 nm) to penetrate standing water and to produce re- 
turns from the underlying substrate. Green LiDAR pulses are often used in conjunction with infrared pulses to measure water depth by producing returns from both the surface and the underlying substrate. Figures 6a and $6 \mathrm{~b}$ were collected using bathymetric LiDAR. These data are subject to some of the same concerns described previously. Green LiDAR will be of limited use in seasonally saturated or seasonally inundated wetlands, depending on the water levels at the time of data collection. Green LiDAR may provide evidence of wetland hydrology in estuarine wetlands if the data were collected during the growing season as described above. All information obtained from topographic datasets collected using green LiDAR must be ground truthed during a field investigation.

Overall, the literature suggests three reasons that neither LiDAR intensity data nor topographic data collected using green LiDAR are reliable enough to constitute a primary indicator of wetland hydrology. First, they provide no information about hydrologic duration or frequency. Second, intensity values of standing water fluctuate with environmental conditions, making it difficult at times to distinguish wetland and nonwetland values. Third, because inundation is seasonal or absent in many wetland types, LiDAR data will classify wetlands as nonwetlands if they were not inundated at the time of data collection. However, LiDAR intensity data could be used as a secondary indicator of wetland hydrology. As a secondary indicator, the patterns of inundation suggested by LiDAR data would have to be confirmed by the presence of another hydrology indicator during the onsite investigation.

\subsection{Conclusions}

In summary, the literature suggests that LiDAR data, products, or models that fuse LiDAR with other remote sensing data to predict the presence of three-factor wetlands will be useful for planning-level efforts. In the preliminary data-gathering stage of wetland delineations, they can be used to divide a project area into LCTs and to model the presence or absence of three-factor wetlands, based on landscape-level patterns in vegetation, topography, and hydrology. Dividing a project area into LCTs based on patterns of vegetation height will be useful only in wetlands characterized by abrupt transition zones. LiDAR will be less useful in distinguishing between wetlands and uplands with the same canopy type. LiDAR data should not be used to make vegetation determinations since they cannot identify plants to species and sometimes cannot detect that vegetation is present. 
LiDAR topographic data can also be used to divide a project area based on changes in topography or slope. Topographic data can be used to map areas with the potential to accumulate water. Point-cloud data and DTMs may be used to measure changes in elevation and to calculate slope. However, these data should not be used as a primary indicator of wetland hydrology, since they cannot detect the presence or absence of water. If the resolution is sufficient, ground-truthed LiDAR data could be used in support of secondary hydrology indicators, such as geomorphic position, microtopographic relief, raised ant mounds, or frost-heave hummocks. Soil or topographic wetness indices derived from LiDAR products cannot be used to determine if a hydric soil is present; however, they may predict areas in which soils are likely to be saturated. Because wetness indices are developed from different types of topographic data collected at different spatial scales, it is important to confirm before using it in a preliminary investigation that a wetness index was derived from LiDAR data.

Provided that LiDAR intensity data were collected during the growing season, they could be used as a secondary indicator of wetland hydrology. Intensity data identify areas that were ponded or inundated on the survey date. However, intensity data alone cannot be used to determine if wetland hydrology is present as they represent a single collection date and contain no information regarding duration or frequency of inundation. For two reasons, intensity values should not be used as evidence that wetland hydrology is not present. First, intensity data cannot identify seasonally inundated or saturated wetlands that lack standing water. In addition, under certain environmental conditions, standing water and wetlands may produce strong intensity values similar to those produced in uplands. For these reasons, all areas identified as wetland and nonwetland by intensity data must be ground truthed during the field investigation. 


\section{References}

Anderson, K., J. Bennie, E. Milton, P. Hughes, R. Lindsay, and R. Meade. 2010. Combining LiDAR and IKONOS data for eco-hydrological classification of an ombrotrophic peatland. J ournal of Environmental Quality 39:260- 273.

Applied Imagery. 2012. Quick Terrain Reader 7.1.6. Silver Spring, MD: J ohns Hopkins Applied Physics Laboratory.

Bailly, J . S., P. Lagacherie, C. Millier, C. Puech, and P. Kosuth. 2008. Agrarian landscapes linear features detection from LiDAR: Application to artificial drainage networks. International J ournal of Remote Sensing 29:3489- 3508.

Blue Marble Geographics. 2012. Global Mapper v.13. Hallowell, ME: Blue Marble Geographics.

Böhner, J ., R. Koethe, O. Conrad, J . Gross, A. Ringeler, and T. Selige. 2002. Soil regionalisation by means of terrain analysis and process parameterisation. In Soil Classification 2001, ed. E. Micheli, F. Nachtergaele, and L. Montanarella. Research Report No. 7, EUR 20398, 213-222. Luxembourg: European Soil Bureau.

Bork, E., and J . Su. 2007. Integrating LiDAR data and multispectral imagery for enhanced classification of rangeland vegetation: A meta analysis. Remote Sensing of Environment 111:11- 24.

Brennan, R., and T. Webster. 2006. Object-oriented land cover classification of LiDARderived surfaces. Canadian J ournal of Remote Sensing 32:162- 172.

Casas, A., G. Benito, V. Thorndycraft, and M. Rico. 2006. The topographic data source of digital terrain models as a key element in the accuracy of hydraulic flood modelling. Earth Surface Processes and Landforms 31:444- 456.

Chust, G., I. Galparsoro, A. Borja, J . Franco, and A. Uriarte. 2008. Coastal and estuarine habitat mapping, using LiDAR height and intensity and multi-spectral imagery. Estuarine, Coastal and Shelf Science 78:633-643.

Clark, M., D. Clark, and D. Roberts. 2004. Small footprint LiDAR estimation of subcanopy elevation and tree height in a tropical rain forest landscape. Remote Sensing and the Environment 91:68-89.

Curtis, K., R. Lichvar, and L. Dixon. 2011. Ordinary high flows and the stage-discharge relationship in the Arid West Region. ERDC/CRREL TR-11-12. Hanover, NH: US Army Engineer Research and Development Center.

Deems, J., T. Painter, and D. Finnegan. 2013. LiDAR measurement of snow depth: A review. J ournal of Glaciology 59:467- 479.

Eamer, J ., and I. Walker. 2010. Quantifying sand storage capacity of large woody debris on beaches using LiDAR. Geomorphology 118:33- 47. 
Environmental Laboratory. 1987. Corps of Engineers wetlands delineation manual. Technical Report Y-87-1. Vicksburg, MS: Environmental Laboratory, US Army Corps of Engineers Waterways Experiment Station. http://el.erdc.usace.army.mil/elpubs/pdf/wlman87.pdf (accessed 19 November 2010).

Environmental Systems Resource Institute (ESRI). 2011. ArcGIS Desktop: Release 10.1. Redlands, CA: Environmental Systems Research Institute.

Enwright, N., M. Forbes, R. Doyle, B. Hunter, and W. Forbes. 2011. Using geographic information systems (GIS) to inventory coastal prairie wetlands along the upper Gulf Coast, Texas. Wetlands 31:687-697.

Farid, A., D. Rautenkranz, D. Goodrich, S. Marsh, and S. Sorooshian. 2006. Riparian vegetation classification from aerial laser scanning data with an emphasis on cottonwood trees. Canadian J ournal of Remote Sensing 32:15- 18.

Federal Emergency Management Agency (FEMA). 2010. LiDAR specifications for flood hazard mapping, 11-Aug-2010. Washington, DC: Federal Emergency Management Agency. http://www.fema.gov/national-flood-insurance-program-0/lidarspecifications-flood-hazard-mapping/lidar-specifications (accessed 6 February 2012).

Federal Geographic Data Committee (FGDC). 2009. Wetlands mapping standard. FGDC Document Number FGDC-STD-015-2009. Reston, VA: Federal Geographic Data Committee, Wetland Subcommittee. http://www.fws.gov/wetlands/Documents/FGDCWetlands-Mapping-Standard.pdf (accessed August 2012).

Finnegan, D. 2012. Personal Communication with J . Gillrich. 14 February. Hanover, NH: US Army Engineer Research and Development Center.

Frazier, P., D. Ryder, E. McIntyre, and M. Stewart. 2012. Understanding riverine habitat inundation patterns: Remote sensing tools and techniques. Wetlands 32:225237.

Garroway, K., C. Hopkinson, and R. J amieson. 2011. Surface moisture and vegetation influences on LiDAR intensity data in an agricultural watershed. Canadian J ournal of Remote Sensing 37:275- 284.

Geerling, G., M. Labrador-Garcia, J . Clevers, A. Ragas, and A. Smits. 2007. Classification of floodplain vegetation by data fusion of spectral (CASI) and LiDAR data. International J ournal of Remote Sensing 28:4263-4284.

Gesch, D. 2007. The National Elevation Dataset. In Digital Elevation Model Technologies and Applications: The DEM Users Manual, ed. D. Maune. 2nd ed. Bethesda, MD: American Society for Photogrammetry and Remote Sensing.

Gilmore, M., E. Wilson, N. Barrett, D. Civco, S. Prisloe, J . Hurd, and C. Chadwick. 2008. Integrating multi-temporal spectral and structural information to map wetland vegetation in a lower Connecticut River tidal marsh. Remote Sensing of Environment 112:4048-4060.

Hall, R., R. Watkins, D. Heggem, K. J ones, P. Kaufmann, S. Moore, and S. Gregory. 2009. Quantifying structural physical habitat attributes using LiDAR and hyperspectral imagery. Environmental Monitoring and Assessment 159:63- 83. 
Henry, R., and L. Gonzalez. 2005. Use of LiDAR in wetland delineation on West Galveston Island, Texas. Houston, TX: USGS National Biological Information Infrastructure, Central Southwest Gulf Coast Information Node, Houston Advanced Research Center. http://cswgcin.harc.edu/docs/LIDARwhitepaper.pdf (accessed August 2012).

Heritage, G., and D. Milan. 2009. Terrestrial laser scanning of grain roughness in a gravel-bed river. Geomorphology 113:4- 11.

Hodge, R., J . Brasington, and K. Richards. 2009a. In situ characterization of grain-scale fluvial morphology using terrestrial laser scanning. Earth Surface Processes and Landforms 34:954-968.

Hodge, R., J . Brasington, and K. Richards. 2009b. Analyzing laser-scanned digital terrain models of gravel bed surfaces: Linking morphology to sediment transport processes and hydraulics. Sedimentology 56:2024- 2043.

Hogg, A., and J . Holland. 2008. An evaluation of DEMs derived from LiDAR and photogrammetry for wetland mapping. The Forestry Chronicle 84:840-849.

Hopkinson, C., L. Chasmer, G. Zsigovics, I. Creed, M. Sitar, P. Treitz, and R. Maher. 2004. Errors in LiDAR ground elevation and wetland vegetation height estimates. In Proceedings of the ISPRS working group VIII/ 2, Laser-Scanners for Forest and Landscape Assessment, 3- 6 October.

Hopkinson, C., M. Hayashi, and D. Peddle. 2009. Comparing alpine watershed attributes from LiDAR, photogrammetric, and contour-based digital elevation models. Hydrological Processes 23:451- 463.

J enkins, R. B., and P. S. Frazier. 2010. High-resolution remote sensing of upland swamp boundaries and vegetation for baseline mapping and monitoring. Wetlands 30:531- 540 .

Jones, A., P. Brewer, E. J ohnstone, and M. Macklin. 2007. High-resolution interpretative geomorphological mapping of river valley environments using aerial LiDAR data. Earth Surface Processes and Landforms 32:1574- 1592.

J ones, K., G. Poole, S. O’Daniel, L. Mertes, and J . Stanford. 2008. Surface hydrology of low-relief landscapes: Assessing surface water flow impedance using LiDARderived digital elevation models. Remote Sensing of Environment 112:41484158.

Kartesz, J . T. 2009. Floristic Synthesis of North America. Version 1.0. Chapel Hill, NC: Biota of North America Program (BONAP).

Kinzel, P. J., C. W. Wright, J . M. Nelson, and A. R. Burman. 2007. Evaluation of an experimental LiDAR for surveying a shallow, braided, sand-bedded river. J ournal of Hydraulic Engineering 133:838- 842.

Klemas, V. 2011. Remote sensing techniques for studying coastal ecosystems: An overview. J ournal of Coastal Research 27:2-17.

Lang, M., and G. McCarty. 2009. LiDAR intensity for improved detection of inundation below the forest canopy. Wetlands 29:1166- 1178 . 
Lang, M., O. McDonough, G. McCarty, R. Osterling, and B. Wilen. 2012. Enhanced detection of wetland stream connectivity using LiDAR. Wetlands 32:461-473.

Lekson, D. 2012. Personal communication with J . Gillrich. 19 September. Wilmington, NC: Regulatory Field Office, Wilmington District, US Army Corps of Engineers.

Lichvar, R., and S. McColley. 2008. A field guide to the identification of the Ordinary High Water Mark (OHWM) in the Arid West region of the western United States. ERDC/ CRREL TR-08-12. Hanover, NH: US Army Engineer Research and Development Center.

Lichvar, R. and J. Wakeley. 2004. Review of Ordinary high water mark indicators for delineating arid streams in the southwestern United States. ERDC/ CRREL TR04-1. Hanover, NH: US Army Engineer Research and Development Center.

Lichvar, R., D. Finnegan, S. Newman, and W. Ochs. 2006. Delineating and evaluating vegetation conditions of vernal pools using spaceborne and aerial remote sensing techniques, Beale Air Force Base, CA. ERDC/ CRREL TR-06-3. Hanover, $\mathrm{NH}$ : US Army Engineer Research and Development Center.

Lichvar, R., W. Ochs, and S. Gaines. 2008. Evaluation of surface features for delineating the ordinary high water boundary on playas in the arid western United States. Wetlands 28:68-80.

Mallet, C., F. Lafarge, F. Bretar, M. Roux, U. Soergel, and C. Heipke. 2009. A stochastic approach for modeling airborne LiDAR waveforms. In Laserscanning 2009 International Society for Photogrammetry and Remote Sensing, Vol XXXVIII, Part 3/ W8-Paris France, 1-2 September.

Maxa, M., and P. Bolstad. 2009. Mapping northern wetlands with high-resolution satellite images and LiDAR. Wetlands 29:248- 260.

Mersel, M., R. Lichvar, J . Gillrich, and L. Lefebvre. In prep. Occurrence and Distribution of Ordinary High Water Mark Indicators in Non-perennial Stream Systems in the US Western Mountain Region. ERDC/ CRREL TR. Hanover, NH: US Army Engineer Research and Development Center.

Milan, D., G. Heritage, A. Large, and N. Entwistle. 2010. Mapping hydraulic biotopes using terrestrial laser scan data of water surface properties. Earth Surface Processes and Landforms 35:918-931.

Mitsch, W. J ., and J . G. Gosselink. 2000. Wetlands. 3rd ed. New York: J ohn Wiley and Sons.

Moeslund, J ., L. Arge, P. Bøcher, B. Nygaard, and J . Svenning. 2011. Geographically comprehensive assessment of salt-meadow vegetation-elevation relations. Wetlands 31:471- 482 .

Moore, I., P. Gessler, G. Nielsen, and G. Peterson. 1993. Soil attribute prediction using terrain analysis. Soil Science Society of America J ournal 57:443- 452.

Murphy, P., J . Ogilvie, K. Connor, and P. Arp. 2007. Mapping wetlands: A comparison of two different approaches for New Brunswick, Canada. Wetlands 27:845- 854. 
National Oceanic and Atmospheric Administration (NOAA) Coastal Services Center. 2008. LiDAR 101: An introduction to LiDAR technology, data, and applications. Charleston, SC: NOAA Coastal Services Center.

National Digital Elevation Program (NDEP). 2004. Guidelines for digital elevation data. Version 1. http://www.ndep.gov/NDEP_Elevation_Guidelines_Ver1_10May2004.pdf (accessed August 2012).

Natural Resources Conservation Service (NRCS), United States Department of Agriculture. 1994. Soil Survey Geographic (SSURGO) Database for Long Island, New York. https://corpsmap.usace.army.mil/ (accessed 6 February 2012).

Newcomb, D., and M. Lang. 2012. Potential of LiDAR intensity data for improved operational mapping of forested wetlands. National Wetlands Newsletter 34:1923.

Nayegandhi, A., S. Vivekanandan, J . C. Brock, S. Stevens, C. W. Wright, J . M. Bonisteel, D. B. Nagle, X. Yates, and E. S. Klipp. 2010. EAARL coastal topographyGateway National Recreation Area, New J ersey and New York, 2009. 1 DVD. Data Series 525. Denver, CO: US Geological Survey.

Onojeghuo, A., and G. Blackburn. 2011. Optimising the use of hyperspectral and LiDAR data for mapping reed bed habitats. Remote Sensing of Environment 115:20252034.

OpenTopography Facility. 2011. A portal to high-resolution topography data and tools. La J olla, CA: San Diego Supercomputer Center, University of California.

Perroy, R. L., B. Bookhagen, G. P. Asner, and O. A. Chadwick. 2010. Comparison of gully erosion estimates using aerial and ground-based LiDAR on Santa Cruz Island, California. Geomorphology 118:288-300.

Reutebuch, S., R. McGaughey, H. Andersen, and W. Carson. 2003. Accuracy of a highresolution LiDAR terrain model under a conifer forest canopy. Canadian J ournal of Remote Sensing 29:527- 535.

Richardson, M., C. Mitchell, B. Branfireun, and R. Kolka. 2010. Analysis of aerial LiDAR surveys to quantify the characteristic morphologies of northern forested wetlands. J ournal of Geophysical Research 115(G3):1- 16.

Riegl Lasar Measurement Systems. 2012. Technical Data for the LMS-Q68Oi Airborne Laser Scanner. Horn, Austria: Riegl Lasar Measurement Systems. http://www.riegl.com/uploads/tx_pxpriegldownloads/10_DataSheet_LMS-0680i_28-092012.pdf

Russell, P., M. Weatherford, and S. Gale. 2010. Wetland and headwater stream modeling effort for the Carthage pilot project. Presented at the Interagency Coordination Meeting of the North Carolina Department of Environment and Natural Resource's Division of Water Quality and North Carolina Department of Transportation, 13 May.

Sankey, T., and P. Bond. 2011. LiDAR-based classification of sagebrush community types. Rangeland Ecology and Management 64:92-98. 
Shaeffer, D. 2008. Characterizing jurisdictional wetlands using LiDAR. Master's Thesis. Greenville, NC: Department of Geography, East Carolina University.

Shoutis, L., D. Patten, and B. McGlynn. 2010. Terrain-based predictive modeling of riparian vegetation in a northern Rocky Mountain watershed. Wetlands 30:621633.

Su, J., and E. Bork. 2006. Influence of vegetation, slope and LiDAR sampling angle on DEM accuracy. Photogrammetric Engineering and Remote Sensing, 72:12651274.

Tande, G. F., and J. M. Michaelson, ed. 2011. National Wetlands Inventory Program: 2010 Annual Report. Arlington, VA: US Fish and Wildlife Service, Division of Habitat and Resource Conservation, Branch of Resource and Mapping Support.

Terra Metrics. 2010. Google Earth Pro. Mountain View, CA: Terra Metrics.

US Army Corps of Engineers (USACE). 2005. Technical standard for water-table monitoring of potential wetland sites. ERDC TN-WRAP-05-2. Wetland Regulatory Assistance Program. Vicksburg, MS: US Army Engineer Research and Development Center. http://www.dtic.mil/cgi-bin/GetTRDoc?AD=ADA441866.

US Congress. 1977. Federal Water Pollution Control Act. 33 U.S.C. § § 1251- 1387 et seq. (amended 27 December 1977). 95th Congress. http://www.gpo.gov/fdsys/pkg/STATUTE91/pdf/STATUTE-91-Pg1566.pdf (accessed February 2014).

US Fish and Wildlife Service (USFWS). 2012. Wetlands Mapper. National Wetlands Inventory. http://www.fws.gov/wetlands/Data/Mapper.html (accessed J anuary 2012).

US Geological Survey (USGS). 2010. US Geological Survey, National Geospatial Program, LiDAR guidelines and base specification. Version 13. http://lidar.cr.usgs.gov/USGSNGP\%20Lidar\%20Guidelines\%20and\%20Base\%20Specification\%20v13\%28ILMF\%29.pdf (accessed J anuary 2012).

US Geological Survey (USGS). 2011. LiDAR for science and resource management. http://ngom.usgs.gov/dsp/index.php ( accessed J anuary 2012).

Vogelmann, J . E., S. M. Howard, L. Yang, C. R. Larson, B. K. Wylie, and N. Van Driel. 2001. Completion of the 1990s National Land Cover Data Set for the conterminous United States from Landsat Thematic Mapper Data and ancillary data sources. Photogrammetric Engineering and Remote Sensing 67:650- 652.

Woolard, J ., and J . Colby. 2002. Spatial characterization, resolution and volumetric change of coastal dunes using airborne LiDAR: Cape Hatteras, North Carolina. Geomorphology 48:269- 287.

Zhao, Z., G. Benoy, T. L. Chow, H. W. Rees, J . Daigle, and F. Meng. 2010. Impacts of accuracy and resolution of conventional and LiDAR based DEMs on parameters used in hydrologic modeling. Water Resources Management 24:1363- 1380. 


\section{Appendix A: Software for Viewing and Managing LiDAR Data and Products}

This appendix describes some software that can be used to view, analyze, and measure features in LiDAR data and LiDAR-derived. It presents a variety of software, ranging from software for investigators with no GIS background to software for those with a great deal of GIS experience. In each case, either USACE has a license for these programs or the software is a free download.

\section{ArcMap 10.1}

ArcMap 10.1 is GIS software distributed by Environmental Systems Resource Institute (ERSI 2011). ArcGIS supports LiDAR data as LAS or ASCII files. The LAS dataset toolbar enables users to display, thin, edit, and analyze LiDAR point clouds in ArcMap 10.1. Help using this toolbar is available at http://resources.arcgis.com/en/help/main/10.1/index.htm/\#//015w0000003z000000. The ArcGIS 3-D analyst is another software extension that enables the user to create LiDAR products, such as DEMs or contour lines, from point-cloud data and to display, measure, and analyze those products in two dimensions. Common applications include creating intensity images or contour lines and estimating surface slope, canopy cover, or height. Figures 4a and 6a were made using ArcMap 10.0. More information regarding working with LiDAR data in ArcMap 10.1 is located at http://help.arcgis.com/en/arcgisdesktop/10.0/help/index.html\#/ Assessing_lidar_coverage_and _sample_density/00q8000000nm000000/.

Although ArcMap 10.1 is an extremely powerful analysis tool, training is required to use it effectively. USACE offers week-long GIS training courses in ArcMap at the beginner and intermediate levels. A class in Remote Sensing Fundamentals, which covers obtaining, modeling, and analyzing multispectral, hyperspectral, radar, LiDAR, and digital elevation data, is also available. For more information, go to http://ulc.usace.army.mil/CrsSchedule.aspx and click on the letter " $G$ " for ArcMap 10.1 courses (GIS Introduction and GIS Intermediate) or the letter "R" for Remote Sensing. 
A free 60-day trial of ArcMap 10.1 is available at http://www.esri.com/software/arcgis/arcgis-for-desktop/free-trial. Support for trial software is found at http://www.esri.com/apps/products/arcgis/eval10/evalhelp/index.cfm.

\section{ArcGIS Explorer Desktop}

ArcGIS Explorer Desktop is a GIS viewer that provides a less technical alternative to ArcMap 10.1. The program is a free download that is easy to use and requires no background in GIS. ArcGIS Explorer provides access to ready-to-use ArcGIS basemaps and layers online, including World Streets, World Imagery, and World Topographic Maps. Users "fly" to different locations by double clicking on a layer. LiDAR-derived products can be imported into ArcGIS Explorer in KML format, in compressed KMZ format, or as a GPX file. Other types of remotely sensed data in vector (NWI polygons) or raster (aerial imagery) representations can be added to these base layers and displayed in two or three dimensions. ArcGIS Explorer enables the user to view, model, and perform spatial analyses. This program is available at http://www.esri.com/software/arcgis/explorer. Help and support are available at the ArcGIS Online Resource Center:

http://resources.arcgis.com/en/communities/arcgis-explorer-desktop/.

\section{Global Mapper 13/dlgv(32) Global Mapper 13.2}

Global Mapper Software LLC designs, develops, and distributes the Global Mapper software package. Global Mapper imports LiDAR-derived models in raster and vector representations and imports point clouds as LAS or KML files. The program prompts the user to supply any missing information, such as spatial projection. The software can be used to view, measure, and analyze spatial data. Global Mapper connects to the Internet and retrieves background maps, such as aerial imagery, street maps, or topographic maps, such as $10 \mathrm{~m}$ resolution DEMs from NED. However, some of these data, such as $1.0 \mathrm{~m}$ resolution aerial imagery from the National Agriculture Imagery Program, cannot be accessed with the free download version. The $10.0 \mathrm{~m}$ resolution NLCD shown in Figure $6 \mathrm{c}$ was created using Global Mapper 13. The free trial of version 13.2 is available at http://www.bluemarblegeo.com/global-mapper/index.php. This software is also distributed by the USGS under the name dlgv32 Pro at ftp://ftpext.usgs.gov/pub/cr/mo/rolla/viewers/dlgv32pro/. 


\section{Google Earth Pro}

Google Earth Pro (GEP) software enables users to view satellite imagery of locations anywhere on Earth by typing an address into a search box or navigating with a mouse (Terra Metrics 2012). The program is easy to use and requires no background in GIS. Users can quickly navigate through the landscape using a mouse and cursor, or they can "fly" to a location by double clicking on an imported layer. The elevation and the geographic coordinates of each location are displayed at the bottom of the screen. LiDAR-derived products must be converted into KML format before they can be imported into GEP. The program also accepts compressed KMZ files. Imported LiDAR products are displayed over the satellite imagery base map. GEP includes several base layers that may be useful to investigators, including boundaries, roads, and terrain (a layer that enables the viewer to see the terrain in 3D). Other remotely sensed data, such as NWI or soil polygons, can be clipped and imported for analysis with LiDARderived elevation data. Markers can be placed at various points in a project area. Maps are easily exported, printed, and emailed. Figure $6 \mathrm{~b}$ was created using GEP.

\section{Quick Terrain Reader 8.0.2}

Quick Terrain software was developed at J ohns Hopkins University's Applied Physics Lab and is distributed by Applied Imagery, Silver Spring, MD. Quick Terrain Reader (QTR 8.0.2) is the free companion software to Quick Terrain Modeler, a more complex program for editing and modeling LiDAR data and creating two dimensional products. No expertise in GIS is required to operate QTR 8.0.2. This program enables the user to open and view extremely large point clouds or models (LAS files) without having set projections or geographic coordinates. This program can handle models composed of up to 200 million points and point-cloud data composed of up to 100 million points. Users navigate through the landscape using a mouse and cursor. QTR 8.0.2 displays data in three dimensions, so care must be taken to ensure that the user remains on top of the landscape. The software includes tools for measuring length and height. Markers can be placed at various points in the landscape. Figures 2, 3, 4b, and 5 were generated using QTR 7.1.6. The program can be downloaded for free, along with sample LiDAR datasets to explore, at http://www.appliedimagery.com/download.php. 


\section{Appendix B: Some Sources of LiDAR Data}

\section{Data.gov}

The purpose of Data.gov is to increase public access to high-value, machine-readable datasets and to enable the public to find, download, and use these datasets, which are generated by the executive branch of the federal government. Data.gov provides descriptions of the federal datasets (metadata), information about how to access the datasets, and tools that leverage government datasets. The data catalogs will continue to grow as datasets are added. Executive branch data are included in the first version of Data.gov.

There are many types of data available from this site, much of which are not geospatial, such as a list of FDIC failed banks. The fastest way to find LiDAR-derived products is to navigate to the datasets page at http://catalog.data.gov/dataset and to type "LiDAR" into the search box.

\section{Louisiana Statewide GIS}

This website (http://atlas.lsu.edu/lidar/) is maintained and operated by the Computer Aided Design and Geographic Information Systems Research Laboratory at Louisiana State University. A wide variety of geospatial data are available, including LiDAR data. Data can be downloaded as shapefiles with contour lines, as DEMs, and as raw or edited point clouds.

\section{National Center for Airborne Laser Mapping}

The National Center for Airborne Laser Mapping (NCALM) Distribution Center website (http://calm.geo.berkeley.edu/ncalm/ddchtml) is hosted and maintained at the University of California-Berkeley, Department of Earth and Planetary Science, with IT infrastructure support from the Berkeley Seismological Laboratory. It is jointly operated by the Department of Civil and Environmental Engineering, Cullen College of Engineering, University of Houston, and the Department of Earth and Planetary Science, University of California-Berkeley. The National Science Foundation provides funding for this website, which makes aerial laser mapping technology (i.e., LiDAR) available to the scientific community. The datasets were collected under NCALM's graduate student seed proposal program. Each collection 
is typically limited to an area of no more than $40 \mathrm{~km}^{2}$. Figure $3 \mathrm{~b}$ was made from data collected by NCALM.

\section{National Center for Earth-Surface Dynamics}

These stream restoration data were created or compiled by scientists funded by the National Center for Earth-Surface Dynamics (NCED). Registered users may access and download data at https://repository.nced.umn.edu. Not all data are LiDAR-derived. NCED requests that all data obtained from this site be properly cited, including any additional citation accompanying a specific data set.

\section{Natural Resources Conservation Service}

Data from the National Elevation Dataset can be downloaded at Geospatial Data Gateway (http://datagateway.nrcs.usda.gov/) maintained by the US Department of Agriculture, NRCS. To order, select the state and county of your project area. If LiDAR data are available, they will be listed under the elevation data category as "3 Meter."

\section{North Carolina Floodplain Mapping Program}

LiDAR data, aerial imagery, and floodplain maps for every county in North Carolina are accessible through a clickable map (http://www.ncfloodmaps.com/). Data can be downloaded or users can create maps online and download them as PDFs.

\section{OpenTopography Facility}

The OpenTopography Facility is based at the San Diego Supercomputer Center at the University of California, San Diego, and is operated in collaboration with colleagues in the School of Earth and Space Exploration at Arizona State University. Core operational support for OpenTopography comes from the National Science Foundation's Earth Sciences: Instrumentation and Facilities Program and the Office of Cyberinfrastructure. OpenTopography also receives funding from the National Science Foundation and NASA to support research and development activities.

OpenTopography supplies LiDAR data in a variety of manageable formats. The site (http://www.opentopography.org/) features a clickable map that shows locations across the country where LiDAR data are available. LiDAR data and products collected by ALS and TLS can downloaded in many formats, 
including as point clouds (LAS or LAZ), as two-dimensional DEMs in raster format (GeoTIFF, IMG, Arc ASCII Grid), or as Google Earth files (KMZ). After selecting a geographic area, the user is guided through downloading a point cloud or selecting a subset of the data (i.e., last or first returns) to create a custom DTM, DSM, DEM, or TIN. Figure 3b was made from a DEM obtained at this site.

\section{Puget Sound LIDAR Consortium}

The Puget Sound LiDAR Consortium is an informal group of local agency staff and federal research scientists devoted to developing public-domain high-resolution LiDAR topography and derivative products for the Puget Sound region. Participants include Kitsap PUD; Kitsap, Clallam, and Island counties; the City of Seattle; Puget Sound Regional Council; NASA; and the USGS. Registered users may download LAS or ASCII files, DEMs in raster representations, georeferenced topographic images, and other data at http://www.pugetsoundlidar.org.

\section{United States Interagency Elevation Inventory}

The US Interagency Elevation Inventory provides high-accuracy topographic and bathymetric data for the United States and its territories. The project is a joint effort between NOAA and USGS with contributions from FEMA. A clickable map shows the location and types of LiDAR data available, including but not limited to topographic LiDAR, topobathy shoreline LiDAR, and bathymetric LiDAR. The address is

http://www.csc.noaa.gov/inventory/\#.

\section{USACE National Coastal Mapping Program}

The USACE National Coastal Mapping Program is designed to provide high-resolution elevation and imagery data along US shorelines on a recurring basis. The NCMP is executed by the J oint Aerial Lidar Bathymetry Technical Center of Expertise (J ALBTCX). Aerial LiDAR and imagery data are available for many locations in Washington, Oregon, California, on the Gulf and Atlantic Coasts, on the shores of the Great Lakes and on connecting rivers and streams. GIS and LiDAR-derived products include seamless bathy/ topo grids, bare earth bathy/ topo grids, building footprints, a shoreline vector, seafloor reflectance images, basic land cover classifications, and RGB and hyperspectral image mosaics. These data can be accessed by 
going to http://catalog.data.gov/dataset and typing "J ALBTCX + LiDAR" into the search box.

\section{USGS CLICK}

The goal of the USGS Center for LiDAR Information Coordination and Knowledge (CLICK) (http://lidar.cr.usgs.gov/index.php) is to facilitate data access, user coordination, and education of LiDAR remote sensing for scientific needs.

The LiDAR data viewer (http://earthexplorer.usgs.gov/) shows areas of the US for which LiDAR data are available. Check the box marked "LiDAR" under the tab marked "Data Sets." Select a state from the drop-down box under the tab marked "Additional Criteria." Then click the "Results" tab.

\section{USGS-NPS-NASA EAARL}

LiDAR data acquired by the USGS-NPS-NASA using NASA's Experimental Airborne Advanced Research LiDAR (EAARL) system in a variety of coastal environments are available at

http://ngom.usgs.gov/dsp/data/products_year.php. This project is a collaboration among the USGS Coastal and Marine Geology Program's Integrated Remote Sensing and Modeling Group, NASA's Wallops Flight Facility, and the National Park Service's (NPS) Inventory and Monitoring Program. Figures $5 \mathrm{a}$ and $5 \mathrm{~b}$ were made from data downloaded from this site.

\section{USGS National Map Seamless Server}

Both LiDAR-derived and non-LiDAR-derived elevation data are available for download on the Seamless Server Data Warehouse at http://nationalmap.gov/viewer.html. Click the box marked "Elevation Availability." To see LiDAR coverage areas, click the box marked NED 1/9 3 meter Staged to see locations where LiDAR data are available. These data can be extracted from the National Map Seamless Server by highlighting an area of interest and clicking the download button at http://viewer.nationalmap.gov/viewer/.

\section{Wikipedia}

Wikipedia lists a number of LiDAR data sets by state and county and provides links to the data. These tables were created from an American Society for Photogrammetry and Remote Sensing publication and from NOAA's 
Topographic and Bathymetric Data Inventory and are found at http://en.wikipedia.org/wiki/National_Lidar_Dataset_(United_States). 


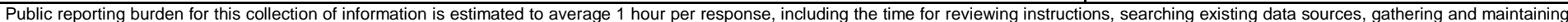

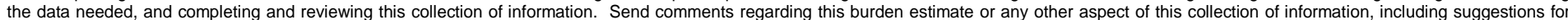

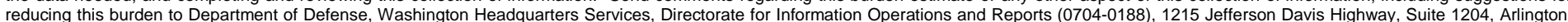

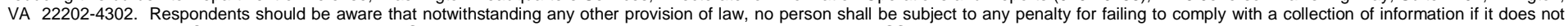
display a currently valid OMB control number. PLEASE DO NOT RETURN YOUR FORM TO THE ABOVE ADDRESS.

\begin{tabular}{l|l}
$\begin{array}{l}\text { 1. REPORT DATE }(D D-M M-Y Y Y Y) \\
\text { 26-03-2014 }\end{array}$ & $\begin{array}{l}\text { 2. REPORT TYPE } \\
\text { Technical Report/Final }\end{array}$ \\
\hline
\end{tabular}

4. TITLE AND SUBTITLE

Use of LiDAR to Assist in Delineating Waters of the United States, Including Wetlands

3. DATES COVERED (From - To)

5a. CONTRACT NUMBER

5b. GRANT NUMBER

5c. PROGRAM ELEMENT NUMBER

6. AUTHOR(S)

5d. PROJECT NUMBER

Jennifer Gillrich and Robert Lichvar

5e. TASK NUMBER

5f. WORK UNIT NUMBER

7. PERFORMING ORGANIZATION NAME(S) AND ADDRESS(ES)

8. PERFORMING ORGANIZATION REPORT NUMBER

Cold Regions Research and Engineering Laboratory (CRREL)

US Army Engineer Research and Development Center

ERDC/CRREL TR-14-3

72 Lyme Road

Hanover, NH 03755-1290

9. SPONSORING I MONITORING AGENCY NAME(S) AND ADDRESS(ES)

10. SPONSOR/MONITOR'S ACRONYM(S)

Wetlands Regulatory Assistance Program (WRAP)

US Army Corps of Engineers

Vicksburg, MS 39180-6133

11. SPONSOR/MONITOR'S REPORT NUMBER(S)

\section{DISTRIBUTION I AVAILABILITY STATEMENT}

Approved for public release; distribution is unlimited.

Available from NTIS, Springfield, Virginia 22161.

13. SUPPLEMENTARY NOTES

\section{ABSTRACT}

During preliminary delineations of an Ordinary High Water Mark (OHWM) boundary, LiDAR data or products may be used to view the OHWM signature across a project area and to estimate the height and location of two primary OHWM indicators: changes in vegetation and breaks in slope. At this time, most LiDAR data or products cannot detect changes in sediment texture. The point spacing, horizontal resolution, and vertical accuracy of the data or products determine if landscape features, such as the OHWM break in slope, can be measured with sufficient accuracy. All information gathered from LiDAR data or products should be verified in the field. During the preliminary, data-gathering stage of wetland delineations, LiDAR data and products may be used to view vegetative, topographic, and hydrologic patterns across a project area and to focus the investigation on transitional areas. They cannot provide evidence of hydrophytic vegetation or hydric soils. Although LiDAR intensity data may provide information on inundation extent, they contain no information regarding inundation frequency or duration and should not be used as a primary hydrology indicator. Intensity data collected during the growing season could be used as a secondary indicator of wetland hydrology. LiDAR data or products are not an adequate substitute for a field investigation.

\section{SUBJECT TERMS $\quad$ Ordinary High Water Mark \\ LiDAR \\ Light Detection and Ranging Systems \\ Wetland Delineation \\ Wetlands}

16. SECURITY CLASSIFICATION OF:

a. REPORT

$\mathrm{U}$

b. ABSTRACT
$\mathrm{U}$

OF ABSTRACT
None

\section{NUMBER} OF PAGES

74 19a. NAME OF RESPONSIBLE PERSON

19b. TELEPHONE NUMBER (include area code) 